\title{
Three-Player Trust Game with Insider Communication
}

\author{
Roman M. Sheremeta \\ and \\ Jingjing Zhang
}

\begin{abstract}
We examine behavior in a three-player trust game in which the first player may invest in the second and the second may invest in the third. Any amount sent from one player to the next is tripled. The third player decides the final allocation among three players. The baseline treatment with no communication shows that the first and second players send significant amounts and the third player reciprocates. Allowing insider communication between the second and the third players increases cooperation between these two. Interestingly, there is an external effect of insider communication: the first player who is outside communication sends $54 \%$ more and receives $289 \%$ more than in the baseline treatment. As a result, insider communication increases efficiency from $44 \%$ to $68 \%$.
\end{abstract}

JEL Classifications: C72, C91, D72

Keywords: three-player trust games, experiments, reciprocity, communication 


\section{INTRODUCTION}

Trust and reciprocity play important roles in economic interactions. The most frequently used measure of trust and reciprocity in economics is based on a two-player trust game, proposed by Berg et al. (1995). In this game, the first player (trustor) sends any part of his endowment to the second player (trustee). The amount sent is tripled and the second player decides how much to return. Berg et al., as well as many replications, show that most participants display trust and trustworthiness contrary to self-interested profit-maximizing behavior (McCabe et al., 1998, 2000, 2003; Glaeser et al., 2000; Burks et al., 2003). However, the bilateral relation in the twoplayer trust game rules out the multiple levels of trust that often emerge in real life when more than two agents are involved. For example, customers trust that the retailer will link them to a reliable producer. Safari travelers rely on their domestic travel company to match them with a high-quality foreign travel agent in Africa. Web businesses connect people with hotels, houses, condominiums, and other accommodations for rent. In all these relationships, the retailer, the domestic travel company, and the web businesses serve as a middleman linking users to goods and services. Whether or not to purchase via a middleman, depends on the degree to which users are willing to accept vulnerability based on positive expectations of both the middleman and the provider. The redistribution of the benefits in these types of transactions is mainly controlled by the last player in the chain who provides goods or services to the customer and pays a commission to the middleman for making the linkage.

Multi-level trust interactions are also common in financial markets. For example, a person investing in a bond fund must trust the fund manager to correctly represent the bonds in the fund. The fund manager, in turn, must trust the bond issuers. The same intuition applies in the fund of funds (FOF) industry, where the manager of a hedge fund company invests in other 
funds instead of individual securities. Thus, multiple (direct and indirect) levels of trust are required between the individual investor, the hedge fund manager, and the FOF manager. Finally, multi-level trust is crucial in workplaces where the workers must not only trust their managers to report their performance truthfully to the CEO, but also trust that the CEO will appropriately reward their performance.

This study provides a framework for understanding multi-level trust interactions in complex environments involving direct and indirect interactions among multiple players. We depart from the conventional two-player trust game of Berg et al. (1995) by introducing the third player. In our three-player trust game, the three players move sequentially. (1) The first player sends any portion of his endowment to the second player, with the amount being tripled. (2) The second player then decides how much to send to the third player, with the amount being tripled again. (3) Finally, the third player decides the final allocation among three players. The threeplayer trust game captures the essential elements of complex multi-level trusting and reciprocal behavior in a simplified setting.

Moreover, trust in multi-level interactions depends on the thickness and the pattern of the links between players. One of the indispensable social lubricants for the network of trust and reciprocity is communication. The multi-level interactions introduced by adding the third player provide us a useful platform to explore our second research question: what are the internal and external effects of communication on trust and reciprocity. There are many potential channels of communication that one can investigate in the three-player trust game, but the considerable complexity that arises with the introduction of communication is nontrivial. As a first step, we focus on studying communication between the second and the third player which resembles insider communication in a group when only a subgroup is allowed to communicate (as far as we 
know, this is the first laboratory study of insider communication). ${ }^{1}$ In the FOF example, there is a potential for privileged insider communication between the FOF manager and the managers of the hedge funds. Similarly, in the workers-manager-CEO example, the detailed discussions CEO and managers have in the board room are often not revealed to workers.

We conducted treatments with and without insider communication. The results of our experiment indicate that even in the baseline treatment with no communication, the first and second players send significant amounts and the third player reciprocates. When we allow communication between the second and the third player, the amounts sent and returned between these two increase. The new interesting finding is that there is an external effect of insider communication: the first player who is outside communication sends $54 \%$ more and receives 289\% more than in the baseline treatment. As a result, insider communication increases efficiency from $44 \%$ to $68 \%$. Content analysis of the communication reveals that what drives the most efficient outcomes are the proposals of equal split among three players made by either the second or the third player. The effect of these types of proposals is strong enough to overcome tendencies toward collusion between the second and the third player.

Our three-player trust game is related to a three-player centipede game of Rapoport et al. (2003) and Murphy et al. (2004). ${ }^{2}$ The three-player centipede game is a multi-stage game which can be used to address some aspects of indirect trust (Camerer 2003). However, the strategy space of each player in the three-player centipede game is restricted to a binary choice, whether to end the game and take some percentage of the available surplus, or to increase the surplus and allow other players a chance to end the game. Thus, it allows observing only whether indirect trust exists but not the magnitude of indirect trust. The three-player trust game proposed in this study is general enough to capture both the degrees of direct and indirect trust and reciprocity by 
using a continuous strategy space for each player. Moreover, our game gives us the flexibility to analyze different communication channels and, in this paper, we focus on the external effect of insider communication which is new to the communication literature.

\section{THREE-PLAYER TRUST GAME}

We introduce a novel three-player trust game, where player 1 acts as a trustor, player 2 embodies both the trustor's and trustee's characteristics, and player 3 always acts as a trustee. All players 1,2 , and 3 are endowed with $e_{1}, e_{2}$, and $e_{3}$. Player 1 can send a portion $\alpha_{12}$ of his endowment $e_{1}$ to player 2 . The amount sent by player 1 is multiplied by factor $k_{1}$. Then player 2 can send a portion $\alpha_{23}$ of his total income to player 3 . The amount sent by player 2 is multiplied by factor $k_{2}$. Then player 3 can reciprocate to players 1 and 2 by returning portions of the total money received $\left(\alpha_{31}>0\right.$ and $\left.\alpha_{32}>0\right)$. It is important to emphasize that, in returning to player 1 , player 3 may be motivated by direct reciprocity and two types of indirect reciprocity, i.e., observation-based and experience-based. ${ }^{3}$ Moreover, being reciprocal only requires returning positive amounts while being trustworthy requires returning at least as much as the amount received (McCabe et al., 2003).

The unique subgame perfect Nash equilibrium in the three-player trust game, which assumes that all players maximize their earnings, is for all players to send nothing. By backwards induction, player 2 knows that a rational player 3 will not return anything $\left(\alpha_{32}=\alpha_{31}=0\right)$ and therefore player 2 should send nothing $\left(\alpha_{23}=0\right)$. Anticipating this, player 1 should send nothing to player $2\left(\alpha_{12}=0\right)$. In this setting, if player 1 sends any positive amount $\left(\alpha_{12}>0\right)$, it means he is willing to take a risky bet that both players 2 and 3 will reciprocate. In other words, player 1 exhibits direct trust in player 2 and indirect trust in player 3. It is riskier to trust in this game than 
in the two-player game because player 1 is repaid by player 3 and not by player 2 . Therefore, player 1 has to trust that player 2 will pass the money to player 3 and also trust that player 3 will be trustworthy. The most efficient outcome is when both players 1 and 2 fully trust player 3 by sending all of their incomes.

\section{EXPERIMENTAL DESIGN AND HYPOTHESES}

\section{A. Experimental Design}

We conducted an experiment in which each session had two treatments: a no communication treatment $(\mathrm{NC})$ and a communication treatment $(\mathrm{C})$. Both treatments lasted for 10 periods. We used a random stranger protocol with fixed roles. In the NC treatment, all subjects were randomly assigned to a specific role, designated as player 1 , player 2 , or player 3 . Each subject remained in the same role throughout the experiment. At the beginning of each period, each player was endowed with $e_{1}=e_{2}=e_{3}=100$ experimental francs and was randomly regrouped with two other players to form a three-player group, with each player in a different role. Player 1 made a decision on how many francs between 0 and 100 to send to player 2 and how many francs to keep. Each franc sent by player 1 was tripled $\left(k_{1}=3\right)$. After players 2 and 3 learned the amount of francs sent by player 1 , player 2 then made a decision on how many francs to send to player 3 . The amount sent by player 2 was also tripled $\left(k_{2}=3\right)$. Finally, player 3 made a decision on how many francs to return to player 1 , how many francs to return to player 2 , and how many francs to keep. All subjects were told that player 1, player 2, and player 3 can send some, all, or none of the francs available to them. At the end of each period, the amounts sent and returned by all players were reported for everyone to see. Instructions, available in the online Appendix I, explain the structure of the game in detail. 
To study the effects of insider communication we conducted a treatment $\mathrm{C}$. The design of the $\mathrm{C}$ treatment closely followed the design of the NC treatment except that, after player 1 made his decision, player 2 and player 3 were able to communicate for 90 seconds in a text based "chat room". Communication took place only after players 2 and 3 learned the decision made by player 1. Subjects were told that only players 2 and 3 would see the messages. In sending messages back and forth, we requested subjects to be civil to each other and not to reveal their identities.

A total of 72 undergraduate student subjects from Purdue University participated in our experiment. The computerized experimental sessions were run using z-Tree (Fischbacher, 2007). We ran two NC-C sessions, in which a total of 36 subjects were engaged in 10 interactions with no communication and then 10 interactions with communication (NC-C sessions). The other 36 subjects participated in the C-NC sessions, where we reversed the order of the treatments. ${ }^{4}$ After completing all 20 decision periods, 4 periods were randomly selected for payment ( 2 periods for each treatment). The earnings were converted into US dollars at the rate of 100 francs to $\$ 1$. On average, subjects earned $\$ 16$ each and the experiment session lasted for about 90 minutes.

\section{B. Hypotheses}

Previous studies have shown that subjects care about treating others fairly (Fehr and Gachter, 2000a), they display trust and trustworthiness contrary to self-interested profitmaximizing behavior (Berg et al., 1995; McCabe et al., 1998), they are concerned about efficiency (Engelmann and Strobel, 2004), and they have unconditional other-regarding preferences (Fehr and Schmidt, 1999; Bolton and Ockenfels, 2000; Cox, 2004). In evolutionary literature it is found that people exhibit direct and indirect trust in other people (Buchner et al., 
2004; Greiner and Levati, 2005). ${ }^{5}$ Based on these observations we provide the following hypothesis.

Hypothesis 1: Players 1 and 2 trust player 3 by sending positive amounts, and player 3 reciprocates.

It is also documented in a two-player trust game that the levels of direct trust and reciprocity are higher than the levels of indirect trust and reciprocity (Wedekind and Milinski, 2000; Dufwenberg et al., 2001; Guth et al., 2001; Seinen and Schram, 2006). ${ }^{6}$ Therefore, we expect that:

Hypothesis 2: Player 2 trusts more than player 1, and player 3 reciprocates to player 2 more than to player 1 .

We base our hypothesis about the effects of insider communication in the three-player trust game on previous findings in the communication literature. Several experimental studies of one-shot two-player trust games show that communication increases cooperation between trustor and trustee (Glaeser et al., 2000; Buchan et al., 2006; Charness and Dufwenberg, 2006; Ben-Ner and Putterman, 2009; Ben-Ner et al., 2011). ${ }^{7}$ Communication also improves cooperation in prisoner dilemma games (Wichman, 1972), public good games (Isaac and Walker, 1988), common-pool resource games (Hackett et al., 1994), voting experiments (Schram and Sonnemans, 1996; Zhang, 2012), and contests (Sheremeta and Zhang, 2010; Cason et al., 2012). Social psychologists have identified several means by which communication can increase cooperation: communication creates group identity, thus improving group welfare, and communication elicits commitments, creating a promise-keeping norm (Bornstein, 1992; Kerr and Kaufman-Gilliland, 1994; Bicchieri, 2002). In our three-player trust game, insider communication occurs between players 2 and 3. Therefore, we expect that: 
Hypothesis 3: With insider communication, player 2 trusts player 3 more, and player 3 reciprocates more.

According to the social identity theory (Tajfel and Turner, 1979; Chen and Li, 2009), individuals may put themselves and others into different categories based on perceived similarities and differences (categorization), identify others as in-group or out-group members (identification), and discriminate in favor of the in-group and against the out-group members (comparison). Various methods have been used to induce saliency of group identity, including communication between group members (Sutter, 2009; Cason et al., 2012). Since in our experiment insider communication occurs only between players 2 and 3, these players should identify each other as in-group members, while categorizing player 1 as an out-group. Such categorization would imply collusion between players 2 and 3 , and thus less trust from player 1. On the other hand, as discussed previously, communication should enhance trust and trustworthiness between players 2 and 3, thus increasing their payoffs (Ben-Ner et al., 2011). Given that some individuals have preferences for equal distribution of payoffs (Fehr and Schmidt, 1999; Bolton and Ockenfels, 2000), it is likely for players 2 and 3 to share their higher payoffs with player 1, which in turn may increase the trust level of player 1 . In summary, depending on whether the "equal distribution" effect or the "collusion" effect dominates player 1 will either trust more, less or the same. This is an empirical question for us to test against the following null hypothesis.

Hypothesis 4: With insider communication, player 1 trusts the same. 


\section{RESULTS}

Our analysis in Section A focuses on the first 10-period data before switching to a different treatment. We discuss the order effect in details using all 20-period data in Section B. We mainly use parametric tests and multi-level mixed-effects linear regressions to analyze individual decisions. ${ }^{8}$ The regression models have random effects at both the individual level and the session level to control for correlations that may arise between individuals due to the random regrouping within a session over time. The within-subject residuals are estimated as being autoregressive of order 2 to account for the repeated measurement for each individual.

\section{A. Trust and Trustworthiness}

Table 1 summarizes the average amount sent and the profit earned by all players in the $\mathrm{C}$ and NC treatments. Among three players, player 1 earns the lowest profit while player 3 earns the highest profit in the experiment. In line with Hypothesis 1, in the NC treatment, players 1 and 2 trust player 3 by sending significant amounts, and player 3 reciprocates. Moreover, in line with Hypothesis 2, the level of indirect trust exhibited by player 1, which is represented by 39 francs sent to player 2 (39\% of income), is significantly lower than the level of direct trust by player 2 , which is represented by 96 francs sent to player 3 (43\% of income). The reciprocal behavior of player 3 is also in agreement with Hypothesis 2, with player 3 returning more to player 2 than to player 1 (57 versus 35 francs, 10\% versus $7 \%$ of income) but the difference is only marginally significant. ${ }^{9}$ On the other hand, on average, player 3 returns $90 \%$ of the amount received from player 1 but only 59\% of the amount received from player 2 . Thus, in terms of trustworthiness, neither player 1's nor player 2's trust pays off. On average, player 2 passes on $82 \%$ of the tripled 
amount received from player 1 without risking his own endowment. Without communication, efficiency is $44 \%$.

[Table 1 about here]

When insider communication is allowed between players 2 and 3, efficiency increases significantly from $44 \%$ to $68 \%$. This is because on average player 2 sends to player 3 the entire tripled amount received from player 1 plus $50 \%$ of his own endowment. As we will show in Section V, player 1 correctly anticipates the increase in trust player 2 places on player 3 and sends $60 \%$ of his endowment to player 2 (54\% more than in the NC treatment). Player 3 is trustworthy - player 1 receives twice the amount sent and player 2 receives $107 \%$ of the amount sent. Interestingly, the increased trust and trustworthiness do not change the distribution of payoffs among three players.

[Table 2 about here]

Table 2 reports the estimation results of the mixed-effects linear regressions, where the dependent variable is the amount sent by each player in each period and the independent variables are a treatment dummy-variable and a period trend. ${ }^{10}$ As we expected, when communication is allowed, player 2 exhibits more trust in player 3 (specification 2). Controlling for the amount player 2 receives from player 1 , the share of income sent by player 2 is significantly higher in the $\mathrm{C}$ treatment (specification 6). Anticipating this increase, player 1 sends more to player 2 (specifications 1 and 5). Comparing to the NC treatment, player 3 returns higher absolute and relative amounts to players 1 and 2 in the $\mathrm{C}$ treatment (specifications $3,4,7,8$ ). The two panels in Figure 1 show that the distribution of return ratio is shifted towards more generous behavior of player 3 in the $\mathrm{C}$ treatment as compared to the $\mathrm{NC}$ treatment. These findings are consistent with Hypothesis 3. 
[Figure 1 about here]

Although only players 2 and 3 were allowed to communicate, we find that the amount player 1 sends to player 2 in the $\mathrm{C}$ treatment is increased by 54\%. This finding rejects the null Hypothesis 4. We conjectured that the trust level of player 1 would fall in the $\mathrm{C}$ treatment if communication would serve as a collusion device between players 2 and 3. In fact, we do find evidence that insider communication increases the collusion between players 2 and 3 . Table 3 categorizes player 3's decisions conditional on positive amounts sent by players 1 and 2 . In the C treatment, player 3 returns roughly half of his income to player 2 and nothing to player 1 in around $11 \%$ of the time. This did not happen once in the NC treatment. Communication also significantly decreases the percentage of players 3 who are trustworthy to player 1 but not to player 2 and increases the percentage of players 3 who are trustworthy to player 2 but not to player 1 . Then the question is why would communication increase trust of player 1 ? The answer turns out to be very simple. In the NC treatment, player 3 almost never splits the income equally between three players. In the $\mathrm{C}$ treatment, this happens $28 \%$ of the time. Also, there is a significant decrease of the proportion where player 3 keeps everything to himself from $24 \%$ in the $\mathrm{NC}$ treatment to $12 \%$ in the $\mathrm{C}$ treatment and an increase of the proportion where player 3 is trustworthy to both players 1 and 2 . Therefore, in the $\mathrm{C}$ treatment, player 1 receives $288 \%$ more than in the NC treatment. This means that insider communication has two opposite effects on the amount player 3 returns to player 1: (i) insider communication enhances collusion between players 2 and 3, and (ii) it also activates fairness norms and thus increases cooperation between all players. The cooperation effect dominates the collusion effect leading to significant efficiency gains. ${ }^{11}$ The efficiency in the NC treatment is about $44 \%$ while in the $\mathrm{C}$ treatment it is $68 \%$ (see Table 1). Moreover, as a result of communication, all players earn higher payoffs (see Table 1). ${ }^{12}$ 
[Table 3 about here]

To better understand the determinants of trust and trustworthiness, Table 4 reports estimation results of different regression models, where the dependent variable is the amount sent by players 1,2 , and 3 . To control for endogeneity we use three-stage estimation for systems of simultaneous equations with individual subject dummies. Besides a treatment dummy-variable and a period trend, we also include the observable decisions in the current period and the average amounts sent or received by each player across all past periods. ${ }^{13}$ Although we randomly regrouped all players with fixed roles after each period, from specification (1) we see that the amount player 1 sends to player 2 depends on the average amount player 1 received from all previous players 3 . This finding suggests that player 1 is learning about the general level of trustworthiness exhibited by player 3. Similarly, the amount player 2 sends to player 3 depends on the average amount players 3 returned to player 2 in all past periods (specification 2).

[Table 4 about here]

Besides the past observable decisions, specifications (2), (3) and (4) show that the current period's observable choices are significant determinants of the trusting and reciprocal behavior. Specifically, the more player 1 sends to player 2 , the more player 2 passes on to player 3 and the more player 3 returns to player 1. More interestingly, for a given amount that player 2 sends to player 3, the more player 1 sends to player 2, the less player 3 returns to player 2 (specification 3) and the more player 3 returns to player 1 (specification 4). Thus, player 3 reciprocates to player 2 accounting for the decisions made by player 1. In other words, consistent with Nowak and Sigmund (2005), we find evidence for both the observation-based indirect reciprocity (the amount player 3 returns to player 1 increases when player 1 sends more to player 2) and the 
experienced-based indirect reciprocity (the amount player 3 returns to player 2 increases when player 2 sends more to player 3).

\section{B. Order Effects}

We conducted both C-NC sessions and NC-C sessions to examine if there is a significant order effect. Specifically, one interesting question is whether cooperation which subjects achieve during the $\mathrm{C}$ treatment could be sustained in the $\mathrm{NC}$ treatment when communication is removed. Figures $2 \mathrm{a}$ and $2 \mathrm{~b}$ display the time trend of average amount sent by all players in different sessions. Figure $2 \mathrm{a}$ suggests that communication in the $\mathrm{C}$ treatment indeed influences the behavior of players in the consecutive NC treatment. The average amount sent by each player in the NC treatment is higher in the C-NC session (Figure 2a) than in the NC-C session (Figure 2b).

[Figures $2 \mathrm{a}$ and $2 \mathrm{~b}$ about here]

To further account for order effects, Table 5 reports mixed-effects regressions of the amount all players sent on treatment and order variables. Four dummy variables that capture the treatment and order variations are included. The variable $C$-treatment $\times N C-C$ is equal to 1 if treatment is $\mathrm{C}$ and the session is $\mathrm{NC}-\mathrm{C}$. The variable $C$-treatment $\mathrm{x} C$-NC is equal to 1 if treatment is $\mathrm{C}$ and the session is $\mathrm{C}-\mathrm{NC}$. We use the Wald test comparing these two variables to measure the significance of the order effect for the $\mathrm{C}$ treatment (see the second to the last line in Table 5). Similarly, two variables for the NC treatment in the NC-C session and C-NC session are included and the corresponding Wald tests are reported in the last line of Table 5. Clearly, order has a significant effect on the absolute amount sent by all players in both treatments. Particularly, communication is more effective in the NC-C sessions than in the C-NC sessions. A possible explanation is that in the NC-C sessions, after 10 periods of the NC treatment, subjects 
understand better the efficiency cost of poor cooperation, and thus they significantly increase cooperation in the following $\mathrm{C}$ treatment. Although there is a decay of cooperation after we disable communication in the C-NC sessions, the level of cooperation is still significantly higher than in the first half of the NC-C sessions. ${ }^{14}$

[Table 5 about here]

\section{BELIEFS AND MESSAGES}

\section{A. Beliefs}

In both $\mathrm{C}$ and $\mathrm{NC}$ treatments, after making the decision on how much to send to player 2, we asked player 1 to make a prediction about the actions of players 2 and 3 before seeing the outcome screen. ${ }^{15}$ Player 1 was asked to guess how much player 2 would send to player 3 , how much player 3 would return to player 2, and how much player 3 would return to player 1 . Subjects were financially motivated to make correct predictions. They were paid 10 francs for each prediction if the prediction differed by no more than $5 \%$ from the actual decision made. ${ }^{16}$ We chose this belief-elicitation protocol instead of the quadratic-scoring rule mainly because it is simple and rather easy for subjects to understand.

[Table 6 about here]

Table 6 reports the average predictions of player 1 on the amounts sent by player 2 and returned by player 3 and the average percentage differences from the actual decisions made from the first 10 periods. On average player 1 makes good predictions on the amount player 2 sends to player 3 and the amount player 3 returns to player 2 in both $\mathrm{C}$ and $\mathrm{NC}$ treatments. ${ }^{17}$ However, in both treatments, player 1 significantly overestimates the amount player 3 returns to players $1 .^{18}$ 
This overestimation may partially explain the high level of trust exhibited by player 1 in the three-player trust game.

\section{B. Content Analysis of Communication}

At this point we know that insider communication enhances cooperation in the group of three people although only a subgroup of two people is allowed to communicate. This brings us to the question of what kinds of messages cause this cooperation. We use content analysis to answer this question.

\section{[Table 7 about here]}

The procedure that we used to quantify the recorded messages is as follows. First, we randomly selected a session to develop a coding scheme. We classified the messages into 18 categories, shown in Table 7. Then we employed two undergraduate students to code all messages into the coding categories independently. The unit of observation for coding was all messages sent out in a given period before subjects made decisions. Coders were asked not to start coding until they had finished reading all messages in a given period. If a unit of observation was deemed to contain the relevant category of content, it was coded as 1 and 0 otherwise. Each unit was coded under as many or few categories as the coders deemed appropriate. The coders were not informed about any hypotheses of the study. ${ }^{19}$

We use Cohen's Kappa $K$ as a reliability measurement of the between-coder agreement. This measurement determines to which extent the coders agree that a certain message belongs to a particular coding category. Cohen's reliability measurement accounts for the between-coder

agreement by chance (Hayes, 2005). ${ }^{20}$ Reliability $K$ greater than zero indicates that the proportion of agreements exceeds the proportion of agreements expected by chance. According 
to Landis and Koch (1977), $K$ between 0.4 and 0.6 corresponds to a moderate agreement level and $K$ greater than 0.6 corresponds to full agreement. Table 7 displays the coding scheme along with Cohen's reliability indexes and the frequency of coding for the $\mathrm{C}$ treatment. For the vast majority of categories, $K$ is greater than 0.5 . As a result of infrequent coding there are few categories that have unsatisfactory agreement levels. In further discussions of categories we use the average of the two independent codings. Specifically, the value of coding is treated as 1 if two coders agree that a message belongs to a given category, 0 if two coders agree that a message does not belong to a given category and 0.5 if the two coders disagree with each other.

\section{[Table 8 about here]}

Table 8 reports the estimation results of mixed-effects models which have random effects on both the subjects and session levels and account for second-order autocorrelation in the within-subject residuals. The dependent variables are the absolute (specifications 1-3) and relative (specifications 4-6) amounts sent and returned by players 2 and 3 and the independent variables are various categories of messages. In all regressions, we include a trend variable equals the period number and a constant. The first four independent variables code the cases when only one proposal was made and differ by who made the proposal and whether the proposal was to share the profit equally between players 2 and 3 or among all three players. The next two variables quantify the cases when both players 2 and 3 proposed the same strategy. The seventh and eighth variables capture the cases when the two exchanged different proposals - to collude versus to cooperate. The last two message variables are the most frequently coded categories besides making proposals.

There are a number of notable findings. When either player $2(1 \mathrm{a})$ or player $3(2 \mathrm{a})$ or both $(1 \mathrm{a}+2 \mathrm{a})$ propose to collude between themselves, player 3 returns significantly less absolute and 
relative amounts to player 1 (specifications 3 and 6). The collusion proposal significantly increases the amount player 2 sends to player 3 only when both of them proposed it $(1 a+2 a)$ and has a much less effect on the amount player 3 returns to player 2 . When either player 2 (1b) or player $3(2 b)$ or both $(1 b+2 b)$ propose to share equally among all three players, both the absolute and relative amounts player 2 sends to player 3 and player 3 returns to player 1 significantly increase. The cooperative proposal significantly increases the absolute amount player 3 sends to player 2 only when player 2 proposes it and has no effect on the relative amount.

Interestingly, when a collusion proposal is challenged by a cooperative proposal, the negative effect of collusion proposals on the amount player 3 returns to player 1 is offset $(1 \mathrm{a}+2 \mathrm{~b}$, specification 3) or even reversed $(1 b+2 a$, specifications 3 and 6$)$. The positive effect of cooperative proposals on the amount exchanged between players 2 and 3 also disappears.

Finally, promises made by player 3 and appeals made by player 2 do not seem to influence the final decisions.

Therefore, content analysis reveals that the proposals of equal split among three players, especially when such proposals were made by both players or used to challenge the collusion proposal, significantly increase cooperation between all players, and thus efficiency.

\section{CONCLUSIONS}

This paper presents an experimental study of a novel three-player trust game. In this game, player 1 acts as a trustor, player 2 embodies both the trustor's and trustee's characteristics, and player 3 always acts as a trustee. We also investigate the internal and external effects of insider communication on direct and indirect trust and reciprocity. Although the three-player trust game requires additional layers of trust than the standard two-player trust game, we still 
find a substantial level of direct and indirect trust even when there is no communication. Consistent with other studies, we find that the level of direct trust and reciprocity is higher than the level of indirect trust and reciprocity.

Regarding insider communication, we find that players 2 and 3 who are engaged in communication exhibit more trust and trustworthiness. The most unexpected and positive result of our experiment is the effect insider communication has on player 1's behavior. Although only players 2 and 3 are allowed to communicate, we find that player 1's trust increases by 54\%. This is because communication activates stronger preference for fairness than collusion between players 2 and 3. Expecting that, player 1 exhibits more trust in players 2 and 3. In response, player 3 returns higher absolute and relative amounts to player 1. Belief elicitation reveals that player 1 persistently overestimates the trustworthiness of player 3, which may also account for the high level of trust exhibited by player 1 . We also find that the social norms developed during the communication stage carry over to the no communication stage.

Finally, we use content analysis to study what kinds of messages enhance cooperation. In the multivariate analysis of communication, we find that the messages that significantly increase cooperation are the ones that indicate willingness to split all earnings equally.

Our study provides evidence that economic agents exhibit direct and indirect trust in multi-level interactions among strangers. One mechanism that can further promote trust and reciprocity is communication even when only a subgroup of agents can afford to communicate with each other. Since communication between insiders may raise the concerns of forming collusion at the cost of the outsiders, to better use this mechanism, insiders should deliver the idea that communication activates more fairness norms toward the outsiders. This suggests that to build trust with individual investors in FOF, managers have to send clear signals to investors 
that their interests of obtaining cooperative, fair and efficient outcomes from the investment are perfectly aligned.

As a first attempt to use simplified laboratory experiments to explore trusting behaviour and effect of communication in multi-level interactions, caution would be suggested in drawing direct inferences from our results. Nevertheless, our findings may shed some light on the important causal factors affecting the emergence of many web-based auctions and other forms of online businesses which are built on trust and reciprocity among strangers (Resnick and Zeckhauser, 2002). For example, in the wholesale eBay online auction, as a consumer wholesale distributor, you can buy products at an unbeatable wholesale price from suppliers and then set your sale price in online auctions. Advertising fair trade between you and the wholesale suppliers may help to attract more buyers.

There are many interesting extensions to our research. Future work can investigate how trust and reciprocity are affected by different channels of communication, other interactions between players (e.g., player 2 can also directly return to player 1), and factors such as the size of the endowment and multipliers in the three-player trust game. 


\section{References}

Ben-Ner, A., \& Putterman, L. (2009). Trust, Communication and Contracts: An Experiment. Journal of Economic Behavior and Organization, 70, 106-121.

Ben-Ner, A., Putterman, L., \& Ren, T. (2011). Lavish Returns on Cheap Talk: Non-binding Communication in a Trust Experiment. Journal of Socio-Economics, 40, 1-13.

Berg, J., Dickhaut, J., \& McCabe., K. (1995). Trust, Reciprocity, and Social History. Games and Economic Behavior, 10, 122-142.

Bicchieri, C. (2002). Covenants without Swords: Covenants without Swords: Group Identity, Norms, and Communication in Social Dilemmas. Rationality and Society, 14, 192-228.

Blanco, M., Engelmann, D., Koch, A. K., \& Normann, H.T., (2010). Belief Elicitation in Experiments: Is There a Hedging Problem? Experimental Economics, 13, 412-438.

Bolton, G.E., \& Ockenfels, A. (2000). ERC - A Theory of Equity, Reciprocity, and Competition. American Economic Review, 90, 166-93.

Buchan, N., Croson, R., \& Johnson, E. (2006). Let's Get Personal: An International Examination of the Influence of Communication, Culture and Social Distance on Other Regarding Preferences. Journal of Economic Behavior and Organization, 60, 373-98.

Buchner, S., Gonzalez, L.G., Guth, W., \& Levati, M.V. (2004). Incentive Contracts versus Trust in Three-player Ultimatum Games: An Experimental Study. European Journal of Political Economy, 20, 673-694.

Burks, S., Carpenter, J., \& Verhoogen, E. (2003). Playing Both Roles in the Trust Game. Journal of Economic Behavior and Organization, 51, 195-216.

Camerer, C. (2003). Behavioral Game Theory. Princeton University Press. 
Cason, T.N., Sheremeta, R.M., \& Zhang, J. (2012). Communication and Efficiency in Competitive Coordination Games. Games and Economic Behavior, 76, 26-43.

Charness, G., \& Dufwenberg, M. (2006). Promises and Partnership. Econometrica, 74, 15791601.

Chen, Y., \& Li, S.X. (2009). Group Identity and Social Preferences. American Economic Review, 99, 431-57.

Cox, J.C. (2004). How to Identify Trust and Reciprocity. Games and Economic Behavior, 46, 260-281.

Dufwenberg, M., Gneezy, U., Güth, W., \& Van Demme, E. (2001). Direct versus Indirect Reciprocity: An Experiment. Homo Economicus, 18, 19-30.

Engelmann, D., \& Strobel, M. (2004). Inequality Aversion, Efficiency, and Maximin Preferences in Simple Distribution Experiments. American Economic Review, 94, 857-869.

Fehr, E., \& Gachter, S. (2000a). Cooperation and Punishment in Public Goods Experiments. American Economic Review, 90, 980-994.

Fehr, E., \& Gachter, S. (2000b). Fairness and Retaliation: The Economics of Reciprocity. Journal of Economic Perspectives, 14, 159-181.

Fehr, E., \& Schmidt, K.M. (1999). A Theory of Fairness, Competition, and Cooperation. Quarterly Journal of Economics, 114, 817-68.

Fischbacher, U. (2007). z-Tree: Zurich Toolbox for Ready-made Economic Experiments. Experimental Economics, 10, 171-178.

Glaeser, E.L., Laibson, D., Scheinkman, J.A., \& Soutter, C.L. (2000). Measuring Trust. Quarterly Journal of Economics, 65, 811-846. 
Greiner, B., \& Levati, V.M. (2005). Indirect Reciprocity in Cyclical Networks: An Experimental Study. Journal of Economic Psychology, 26, 711-731.

Guth, W., Konigstein, M., Marchand, N., \& Nehring, K. (2001). Trust and Reciprocity in the Investment Game with Indirect Reward. Homo Economicus, 18, 241-262.

Hackett, S., Schlager, E., \& Walker, J. (1994). The Role of Communication in Resolving Commons Dilemmas: Experimental Evidence with Heterogeneous Appropriators. Journal of Environmental Economics and Management, 27, 99-126.

Hayes, A.F. (2005). Statistical Methods for Communication Science. Mahwah, NJ: Erlbaum.

Isaac, R.M., \& Walker, J.M. (1988). Communication and Free-Riding Behavior: The Voluntary Contribution Mechanism. Economic Inquiry, 26, 585-608.

Kerr, N.L., \& Kaufman-Gilliland, C.M. (1994). Communication, Commitment, and Cooperation in Social Dilemmas. Journal of Personality and Social Psychology, 66, 513-529.

Landis, J.R., \& Koch, G.G. (1977). The Measurement of Observer Agreement for Categorical Data. Biometrics, 33, 159-174.

McCabe, K., \& Smith, V. (2000). Goodwill Accounting in Economic Exchange. In: Gigerenzer, G., Selten, R. (Eds.), Bounded Rationality: The Adaptive Toolbox. MIT Press, Cambridge, MA, pp. 319-340

McCabe, K., Rassenti, S., \& Smith, V.L. (1998). Reciprocity, Trust, and Payoff Privacy in Extensive Form Bargaining. Games and Economic Behavior, 24, 10-24.

McCabe, K., Rigdon, M., \& Smith, V.L. (2003). Positive Reciprocity and Intentions in Trust Games. Journal of Economic Behavior and Organization, 52, 267-275.

Murphy, R., Rapoport, A., and Parco, J. E. (2004). Population Learning of Cooperative Behavior in a Three-player Centipede Game. Rationality and Society, 16, 91-120 
Nowak M.A., \& Sigmund, K. (2005). Evolution of indirect reciprocity, Nature, 437, 1292-1298.

Nowak, M.A., \& Sigmund, K. (1998). The Dynamics of Indirect Reciprocity. Journal of Theoretical Biology, 194, 561-574.

Rapoport, A., Stein, W.E., Parco, J.E., \& Nicholas, T.E. (2003). Equilibrium Play and Adaptive Learning in a Three-player Centipede Game. Games and Economic Behavior, 43, 239-65.

Resnick, P., \& Zeckhauser, R. (2002). Trust among strangers in internet transactions: empirical analysis of eBay's reputation system. In: M.R. Baye, Editor, The Economics of the Internet and E-Commerce, Advances in Applied Microeconomics vol. 11.

Schram, A., \& Sonnemans, J. (1996). Why People Vote: Experimental Evidence. Journal of Economic Psychology, 17, 417-442.

Seinen, I., \& Schram, A. (2006). Social Status and Group Norms: Indirect Reciprocity in a Repeated Helping Experiment. European Economic Review, 50, 581-602.

Sheremeta, R.M., \& Zhang, J. (2010). Can Groups Solve the Problem of Over-Bidding in Contests? Social Choice and Welfare, 35, 175-197.

Sutter, M. (2009). Individual Behavior and Group Membership: Comment. American Economic Review, 99, 2247-2257.

Tajfel, H., \& Turner, J. (1979). An Integrative Theory of Intergroup Conflict. In Stephen Worchel and William Austin, eds., The Social Psychology of Intergroup Relations, Monterey, CA: Brooks/Cole.

Wedekind, C., \& Milinski, M. (2000). Cooperation Through Image Scoring in Humans. Science, $288,850-852$.

Wichman, H. (1972). Effects of Isolation and Communication on Cooperation in a Two-player Game, In L.S. Wrightsman, J. O'Connor, and N.J. Baker (Eds.), Cooperation and 
Competition: Readings on Mixed-Motive Games, 197-206. Belmont, CA: Brooks/Cole Publishing Company.

Zhang, J. (2012). Communication in Asymmetric Group Competition over Public Goods. University of Zurich, Working Paper, ECON 69. 


\section{Figure Caption}

FIGURE 1: Distribution of Return Ratio in the NC and C Treatments

FIGURE 2a: Average Amount Sent Over the Periods in C-NC Sessions

FIGURE 2b: Average Amount Sent Over the Periods in NC-C Sessions 


\section{Footnotes}

* The earlier version of this paper circulated under the title "Multi-Level Trust Game with "Insider" Communication." We thank the associate editors and two anonymous referees for helpful comments in revising the manuscript. We also thank Tim Cason, John Dickhaut, Jerry Hurley, Luke Lindsay Stuart Mestelman, Mohamed Shehata, Anya Savikhin, seminar participants at Purdue University and participants at the Economic Science Association meeting for helpful discussions and comments. This research has been supported by the National Science Foundation (SES-0721019). Jingjing Zhang gratefully acknowledges financial support from the European Research Council (ERC Advanced Investigator Grant, ESEI-249433) and Swiss National Science Foundation (SNSF-135135). We alone are responsible for any errors.

\section{Authors:}

Roman M. Sheremeta, Assistant Professor of Economics, Argyros School of Business and Economics, Chapman University, One University Drive, Orange, CA 92866, USA. Phone +1-714-744-7604, Fax +1-714-532-6081, E-mail sheremet@chapman.edu

Jingjing Zhang, Assistant Professor of Economics, Chair for Organizational Design, Department of Economics, University of Zurich, Blümlisalpstrasse 10, CH-8006, Zürich, Switzerland. Phone +41-44-634-3743, Fax +41-44-634-4907, E-mail jingjing.zhang@uzh.ch

1. We chose to study insider communication between players 2 and 3 for several reasons. First, full communication among all players is less feasible in reality and easier to break down as the size of the communicating group grows. Second, restricting communication between insiders 
allows us to examine the impact of such asymmetric communication on both the insiders' and outsiders' behavior. Third, as we discuss in Section III, predictions about the effects of insider communication are not trivial, and thus conducting a laboratory experiment is important.

2. In a repeated three-player centipede game, Rapoport et al. (2003) find that neither full cooperation nor full non-cooperation is supported. In a mixed population of human players and robots, Murphy et al. (2004) find that there is an increase in the propensity of human players to cooperate over time when a handful of cooperative robots are added while adding a handful of non-cooperative robots does not change the cooperation rate.

3. In the terminology of Nowak and Sigmund (2005) there is direct reciprocity and two types of indirect reciprocity, i.e., upstream or observation-based (“A helps B because B helped C") and downstream or experience-based ("A helps B because C helped A"). In our experiment, player 3 may reciprocate to player 1 because player 1 indirectly helped player 3 (direct reciprocity), because player 1 helped player 2 (observation-based indirect reciprocity), and because player 2 helped player 3 (experience-based indirect reciprocity). We report the evidence of the two types of indirect reciprocity in Section IV.

4. Two sessions (one NC-C and one C-NC) had 12 subjects and two other sessions had 24 subjects.

5. Greiner and Levati (2005) use a variant of a trust game in order to implement a cyclical network of indirect reciprocity where the first individual may help the second, the second help the third, and so on until the last, who in turn may help the first. Like in a two-player trust game, the authors find that pure indirect reciprocity enables mutual trust in the multi-player environment. Buchner et al. (2004) compare the trust-reciprocity regimes with the explicit 
incentive schemes in the context of a three-person ultimatum game. They find that mutual trust is as good as incentive contracts in inducing costly actions by employees.

6. Dufwenberg et al. (2001) allow trustees to reciprocate towards the other trustors, and find that indirect reciprocity induces only insignificantly smaller donations than direct reciprocity and that trustees are more rewarding in the case of indirect reciprocity. Guth et al. (2001) find that indirect reward reduces significantly mutual cooperation compared to the direct reward. In the same line of research, Seinen and Schram (2006) and Wedekind and Milinski (2000) provide experimental evidence on indirect reciprocity in the "repeated helping game" developed by Nowak and Sigmund (1998). In this game, donors decide whether or not to provide costly help to the recipients they are matched with, based on information about the recipients' behavior in encounters with third parties.

7. Glaeser et al. (2000) allow face to face communication before playing the trust game. They find that when individuals are closer socially, both trust and trustworthiness increase. They conclude that trusting behavior in the experiments is predicted by past trusting behavior outside of the experiments. Buchan et al. (2006) allow subjects to engage in personal but not taskrelevant communication before playing the trust game and find significant increase of trust and trustworthiness. Charness and Dufwenberg (2006) allow either trustor or trustee, but not both, to send free-form messages in a binary trust game. They find that the messages sent by trustees increase both trust and trustworthiness. However, no such effect is found when only trustors can send messages. Ben-Ner and Putterman (2009) allow two-way communication and find that verbal communication helps subjects to reach agreement even without visual or auditory contact. Similarly, Ben-Ner et al. (2011) allow two-way communication and find that trust and trustworthiness increase when verbal communication is allowed. 
8. For a robustness check, we also estimated panel models with individual subjects representing the random effects (to control for individual effects), standard errors clustered at the session level (to control for possible correlation within a session), and a period trend (to control for learning and experience). The estimation results confirm our main conclusions and are available from the authors upon request. All p-values reported in the paper are two-sided unless otherwise stated. 9. To formally test Hypothesis 2, we estimated the two-level mixed-effects model where the dependent variable is the amount sent per period by players 1 and 2 and the independent variables are a constant, a period variable and a player-type dummy. Based on the estimation, the amount sent by player 1 to player 2 is significantly lower than the amount sent by player 2 to player 3 (p-value $<0.01$ ). The significance disappears when we regress on the share of income sent which accounts for the amount received by player 2 before sending to player 3 . A similar model regressing the amount player 3 returns to players 2 and 1 on the same set of independent variables reports that player 3 sent back marginally more to player 2 than to player 1 (one-sided $\mathrm{p}$-value $=0.10$ ). No significant difference is found based on the relative amount sent by player 3 . 10. The use of non-parametric tests is not feasible in our analyses, as the observations are not independent. Instead we reserve to regressions which control of individual effects (since the same subject makes multiple choices), session effects (since all subjects interact in the same session), and a time trend (since the trust game is repeated).

11. A two sided proportion test indicates that the number of cases where player 3 splits equally between all three players is significant higher than the number of cases where player 3 splits only between players 2 and 3 in $\mathrm{C}$ treatment (p-value $<0.01$ ).

12. Based on the estimation of mixed-effect models where the dependent variables are the period profits for each player and the independent variables are a treatment dummy and a period trend, 
we find that profits are significantly higher in the communication treatment for all player types (p-value $<0.01$ for players 1 and $2, \mathrm{p}$-value $=0.01$ for player 3 ). A similar model regressing total earnings of three players per period on a treatment dummy and a period trend reports significantly positive communication effect ( $\mathrm{p}$-value $<0.01)$.

13. Each subject can see the decisions of all three participants in the group made at each stage from the outcome screen and we asked subjects to write down all the decisions for each period in the personal record sheet.

14. The increase of cooperation when communication is introduced in NC-C sessions and the decay of cooperation when communication is removed in C-NC sessions are similar to the findings with respect to the effect of costly punishment in repeated public goods game with stranger protocol (Fehr and Gachter, 2000b). More interestingly, we find the communication is less effective in C-NC sessions than in NC-C sessions. Such order effect is not observed with the punishment mechanism. Thanks to an anonymous referee for pointing out this analogy.

15. We chose to elicit the beliefs of only player 1 for several reasons. First, the most interesting questions of the current paper are about player 1's behavior, so eliciting player 1's belief was a natural choice. Second, player 1 had the most "free" time in the experiment. After making the decision, player 1 would have to wait for about 5 minutes before players 2 and 3 communicated and made their decisions. The fact that players 2 and 3 were more occupied in our experiment also motivated us not to elicit players 2's and 3's beliefs. Finally, we felt that subjects assigned as player 1 had the least interesting roles, in a sense that they had to make the same unconditional decisions over and over again. So, we decided to provide player 1 with an additional "productive" task. 
16. It is also important to emphasize that eliciting beliefs may cause risk-averse subjects to hedge between choices made in the experiment and incentivized belief statements. However, Blanco et al. (2010) find no evidence of such hedging.

17. Based on the estimation of random effect models, where the dependent variable is the amount predicted minus the actual amount sent, we find that the difference between predicted and actual behavior of player 2 is not significantly different from zero neither in the NC treatment $(\mathrm{p}$-value $=0.14)$ nor in the $\mathrm{C}$ treatment $(\mathrm{p}$-value $=0.92)$. Similarly, the difference between predicted and actual behavior of player 3 towards player 2 is not significantly different from zero neither in the $\mathrm{NC}$ treatment $(\mathrm{p}$-value $=0.34)$ nor in the $\mathrm{C}$ treatment $(\mathrm{p}$-value $=0.83$ ).

18. Based on the estimation of random effect models, where the dependent variable is the amount predicted minus the actual amount sent, we find that the difference between predicted and actual behavior of player 3 towards player 1 is significantly different from zero both in the $\mathrm{NC}$ treatment ( $\mathrm{p}$-value $<0.01)$ and in the $\mathrm{C}$ treatment $(\mathrm{p}$-value $=0.02)$.

19. The instructions for coders are available in the online Appendix II.

20. For binary 0 or 1 coding, agreement by chance is $50 \%$. 
Table 1: Summary of Average Amount Sent and Profit

\begin{tabular}{|c|c|c|c|c|c|c|c|c|c|}
\hline \multirow[t]{2}{*}{ Decision } & \multicolumn{2}{|c|}{ Amount Sent } & \multicolumn{2}{|c|}{ Share of Income Sent } & \multirow[t]{2}{*}{ Player } & \multicolumn{2}{|c|}{ Profit } & \multicolumn{2}{|c|}{$\begin{array}{l}\text { Share of } \\
\text { Total Profit }\end{array}$} \\
\hline & $\mathrm{NC}$ & $\mathrm{C}$ & $\mathrm{NC}$ & $\mathrm{C}$ & & $\mathrm{NC}$ & $\mathrm{C}$ & $\mathrm{NC}$ & $\mathrm{C}$ \\
\hline P1 to P2 & $39(39)$ & $60(40)$ & $0.39(0.39)$ & $0.60(0.40)$ & P1 & 96 & 176 & 0.20 & 0.20 \\
\hline $\mathrm{P} 2$ to $\mathrm{P} 3$ & 96 (107) & $231(143)$ & $0.43(0.40)$ & $0.82(0.32)$ & $\mathrm{P} 2$ & 178 & 297 & 0.33 & 0.35 \\
\hline $\mathrm{P} 3$ to $\mathrm{P} 1$ & $35(61)$ & $136(172)$ & $0.07(0.11)$ & $0.14(0.15)$ & P3 & 296 & 410 & 0.47 & 0.45 \\
\hline $\mathrm{P} 3$ to $\mathrm{P} 2$ & 57 (111) & 247 (189) & $0.10(0.15)$ & $0.30(0.18)$ & Efficiency, \% & 43.8 & 67.9 & & \\
\hline
\end{tabular}

Note: Standard deviations are in parentheses.

Table 2: Treatment Effects

\begin{tabular}{|c|c|c|c|c|c|c|c|c|}
\hline Regression & (1) & (2) & (3) & (4) & (5) & (6) & $(7)$ & $(8)$ \\
\hline \multirow{2}{*}{ Dependent variable } & \multicolumn{4}{|c|}{ Amount Sent } & \multicolumn{4}{|c|}{ Amount Sent Relative to Income } \\
\hline & P1 to P2 & $\mathrm{P} 2$ to $\mathrm{P} 3$ & P3 to P1 & $\mathrm{P} 3$ to $\mathrm{P} 2$ & P1 to P2 & $\mathrm{P} 2$ to $\mathrm{P} 3$ & P3 to P1 & $\mathrm{P} 3$ to $\mathrm{P} 2$ \\
\hline $\begin{array}{l}\text { C-treatment } \\
{[1 \text { if } \mathrm{C} \text { treatment }]}\end{array}$ & $\begin{array}{l}18.29^{*} \\
(10.32)\end{array}$ & $\begin{array}{c}131.57 * * * \\
(30.95)\end{array}$ & $\begin{array}{c}100.11 * * * \\
(27.38)\end{array}$ & $\begin{array}{c}189.22 * * * \\
(36.28)\end{array}$ & $\begin{array}{l}0.18^{*} \\
(0.10)\end{array}$ & $\begin{array}{c}0.39 * * * \\
(0.10)\end{array}$ & $\begin{array}{l}0.07 * * \\
(0.03)\end{array}$ & $\begin{array}{c}0.20 * * * \\
(0.04)\end{array}$ \\
\hline $\begin{array}{l}\text { Period } \\
\text { [period trend] }\end{array}$ & $\begin{array}{c}0.11 \\
(1.08)\end{array}$ & $\begin{array}{l}5.71 * \\
(3.33)\end{array}$ & $\begin{array}{l}-0.72 \\
(2.88)\end{array}$ & $\begin{array}{c}5.04 \\
(3.91)\end{array}$ & $\begin{array}{c}0.00 \\
(0.01)\end{array}$ & $\begin{array}{l}0.02 * * \\
(0.01)\end{array}$ & $\begin{array}{c}-0.01 * * \\
(0.00)\end{array}$ & $\begin{array}{c}0.00 \\
(0.00)\end{array}$ \\
\hline Constant & $\begin{array}{l}41.18 * * * \\
(9.58)\end{array}$ & $\begin{array}{c}66.50 * * \\
(28.53)\end{array}$ & $\begin{array}{l}39.55 \\
(25.02)\end{array}$ & $\begin{array}{c}29.66 \\
(33.46)\end{array}$ & $\begin{array}{c}0.41 * * * \\
(0.10)\end{array}$ & $\begin{array}{c}0.33^{* * * *} \\
(0.09)\end{array}$ & $\begin{array}{c}0.10^{* * * *} \\
(0.03)\end{array}$ & $\begin{array}{l}0.08 * * \\
(0.04)\end{array}$ \\
\hline Observations & 240 & 240 & 240 & 240 & 240 & 240 & 240 & 240 \\
\hline
\end{tabular}

Note: All regressions are estimated using mixed-effects. The models have random effects at both the individual level and the session level and account for second-order autocorrelation in the within-individual residuals. Standard errors are in parentheses. Significance levels are: * significant at $10 \% ; * *$ significant at 5\%; *** significant at $1 \%$.

Table 3: Player 3's Reciprocal Behavior

\begin{tabular}{lccc}
\hline \hline Classification of Player 3's behavior & NC treatment & C treatment & Z-stat \\
\hline P3 sent nothing to P1 and split (almost) equally between P2 and P3 & $0.0 \%$ & $11.3 \%$ & \\
P3 split (almost) equally between P1, P2 and P3 & $0.0 \%$ & $27.8 \%$ & \\
P3 kept everything & $23.5 \%$ & $12.4 \%$ & $-1.88^{*}$ \\
P3 was trustworthy both to P1 and P2 & $16.2 \%$ & $26.8 \%$ & $1.61^{*}$ \\
P3 was trustworthy to P1 but not to P2 & $45.6 \%$ & $7.2 \%$ & $-5.76^{* * *}$ \\
P3 was trustworthy to P2 but not to P1 & $2.9 \%$ & $9.3 \%$ & $1.61^{*}$ \\
P3 was trustworthy neither to P1 nor to P2 & $11.8 \%$ & $5.2 \%$ & -1.55 \\
\hline Observations & 68 & 97 & $4.04^{* * *}$ \\
\hline
\end{tabular}

Note: We only included cases where both players 1 and 2 sent a positive amount. The amount differs less than $10 \%$ is counted as almost equal. The Z-stat reflects the two sample test of proportions. Significance levels are: * significant at $10 \%$; ** significant at $5 \%$; *** significant at $1 \%$. 
Table 4: Determinants of Trust and Trustworthiness

\begin{tabular}{|c|c|c|c|c|}
\hline Regression & $(1)$ & (2) & (3) & (4) \\
\hline Dependent variable & $\mathrm{P} 1$ to $\mathrm{P} 2$ & $\mathrm{P} 2$ to $\mathrm{P} 3$ & $\mathrm{P} 3$ to $\mathrm{P} 2$ & $\mathrm{P} 3$ to $\mathrm{P} 1$ \\
\hline $\begin{array}{l}\mathrm{P} 1 \text { to } \mathrm{P} 2 \\
\text { [P1 to } \mathrm{P} 2 \text { in the current period] }\end{array}$ & & $\begin{array}{c}1.77 * * * \\
(0.11)\end{array}$ & $\begin{array}{l}-0.75^{* * * *} \\
(0.14)\end{array}$ & $\begin{array}{c}0.41 * * * \\
(0.13)\end{array}$ \\
\hline $\begin{array}{l}\mathrm{P} 2 \text { to } \mathrm{P} 3 \\
\qquad[\mathrm{P} 2 \text { to } \mathrm{P} 3 \text { in the current period] }\end{array}$ & & & $\begin{array}{c}0.89 * * * \\
(0.04)\end{array}$ & $\begin{array}{c}0.51 * * * \\
(0.04)\end{array}$ \\
\hline $\begin{array}{l}\mathrm{P} 1 \text { to } \mathrm{P} 2 \text { lag } \\
\quad[\mathrm{P} 1 \text { to } \mathrm{P} 2 \text { average over all past periods] }\end{array}$ & $\begin{array}{l}-0.09 \\
(0.11)\end{array}$ & $\begin{array}{c}-0.75^{* * *} \\
(0.28)\end{array}$ & $\begin{array}{l}-0.24 \\
(0.32)\end{array}$ & $\begin{array}{c}0.09 \\
(0.29)\end{array}$ \\
\hline $\begin{array}{l}\mathrm{P} 2 \text { to } \mathrm{P} 3 \mathrm{lag} \\
\text { [P2 to } \mathrm{P} 3 \text { average over all past periods] }\end{array}$ & $\begin{array}{c}0.00 \\
(0.03)\end{array}$ & $\begin{array}{c}0.23 * * \\
(0.11)\end{array}$ & $\begin{array}{l}-0.09 \\
(0.11)\end{array}$ & $\begin{array}{l}-0.08 \\
(0.10)\end{array}$ \\
\hline $\begin{array}{l}\mathrm{P} 3 \text { to } \mathrm{P} 1 \text { lag } \\
\quad[\mathrm{P} 3 \text { to } \mathrm{P} 1 \text { average over all past periods] }\end{array}$ & $\begin{array}{c}0.06 * * * \\
(0.02)\end{array}$ & $\begin{array}{l}-0.02 \\
(0.06)\end{array}$ & $\begin{array}{l}-0.04 \\
(0.07)\end{array}$ & $\begin{array}{c}0.18 * * * \\
(0.07)\end{array}$ \\
\hline $\begin{array}{l}\mathrm{P} 3 \text { to } \mathrm{P} 2 \text { lag } \\
\quad[\mathrm{P} 3 \text { to } \mathrm{P} 2 \text { average over all past periods] }\end{array}$ & $\begin{array}{c}0.00 \\
(0.02)\end{array}$ & $\begin{array}{c}0.14 * * \\
(0.06)\end{array}$ & $\begin{array}{c}0.24 * * * \\
(0.07)\end{array}$ & $\begin{array}{c}0.06 \\
(0.06)\end{array}$ \\
\hline $\begin{array}{l}\text { C-treatment } \\
\qquad[1 \text { if } \mathrm{C} \text { treatment }]\end{array}$ & $\begin{array}{c}30.69^{* * *} \\
(5.14)\end{array}$ & $\begin{array}{c}52.92 * * * \\
(15.39)\end{array}$ & $\begin{array}{c}77.93 * * * \\
(15.99)\end{array}$ & $\begin{array}{c}-9.97 \\
(14.73)\end{array}$ \\
\hline $\begin{array}{l}\text { Period } \\
\text { [period trend] }\end{array}$ & $\begin{array}{c}-1.97 * * * \\
(0.57)\end{array}$ & $\begin{array}{l}-2.23 \\
(1.60)\end{array}$ & $\begin{array}{c}-4.29 * * \\
(1.81)\end{array}$ & $\begin{array}{c}-5.79 * * * \\
(1.67)\end{array}$ \\
\hline Constant & $\begin{array}{c}50.71 * * * \\
(6.01)\end{array}$ & $\begin{array}{c}49.08 * * * \\
(16.40)\end{array}$ & $\begin{array}{l}32.42 * \\
(18.63)\end{array}$ & $\begin{array}{c}-4.62 \\
(17.16)\end{array}$ \\
\hline Observations & 648 & 648 & 648 & 648 \\
\hline R-squared & 0.30 & 0.59 & 0.68 & 0.53 \\
\hline
\end{tabular}


Table 5: Treatment and Order Effects

\begin{tabular}{|c|c|c|c|c|c|c|c|c|}
\hline Regression & $(1)$ & $(2)$ & $(3)$ & $(4)$ & $(5)$ & $(6)$ & $(7)$ & $(8)$ \\
\hline \multirow{2}{*}{ Dependent variable } & \multicolumn{4}{|c|}{ Amount Sent } & \multicolumn{4}{|c|}{ Amount Sent Relative to Income } \\
\hline & $\mathrm{P} 1$ to $\mathrm{P} 2$ & P2 to P3 & P3 to P1 & $\mathrm{P} 3$ to $\mathrm{P} 2$ & $\mathrm{P} 1$ to $\mathrm{P} 2$ & $\mathrm{P} 2$ to $\mathrm{P} 3$ & P3 to P1 & $\mathrm{P} 3$ to $\mathrm{P} 2$ \\
\hline C-treatment x NC-C & $38.71 * * *$ & $171.62 * * *$ & $130.86 * * *$ & $175.25 * * *$ & $0.39 * * *$ & $0.25 * *$ & 0.01 & $0.12 * * *$ \\
\hline [1 if C treatment and NC-C session] & $(9.73)$ & $(32.20)$ & $(32.37)$ & $(37.57)$ & $(0.10)$ & $(0.11)$ & $(0.04)$ & $(0.04)$ \\
\hline $\mathrm{C}$-treatment $x \mathrm{C}$-NC & -2.57 & 37.16 & -54.31 & 62.15 & -0.03 & 0.13 & $-0.10 * * *$ & $0.10 * * *$ \\
\hline [1 if C treatment and C-NC session] & $(8.35)$ & $(29.11)$ & $(33.82)$ & $(37.85)$ & $(0.08)$ & $(0.08)$ & $(0.03)$ & $(0.04)$ \\
\hline NC-treatment $x$ NC-C & -13.74 & -56.45 & $-99.17 * *$ & $-125.72 * * *$ & -0.14 & $-0.19 *$ & $-0.17 * * *$ & $-0.10 * *$ \\
\hline [1 if NC treatment and NC-C session] & $(11.12)$ & $(37.53)$ & $(41.38)$ & $(46.74)$ & $(0.11)$ & $(0.11)$ & $(0.05)$ & $(0.05)$ \\
\hline NC-treatment $x$ C-NC & $68.00 * * *$ & $207.39 * * *$ & $222.81 * * *$ & $215.88 * * *$ & $0.68 * * *$ & $0.67 * * *$ & $0.30 * * *$ & $0.21 * * *$ \\
\hline [1 if NC treatment and C-NC session] & $(11.60)$ & $(39.79)$ & $(46.40)$ & $(51.66)$ & $(0.12)$ & $(0.11)$ & $(0.05)$ & $(0.05)$ \\
\hline Period & $-1.68 * * *$ & $-5.10 * *$ & $-9.49 * * *$ & $-6.08 * *$ & $-0.02 * * *$ & -0.00 & $-0.01 * * *$ & -0.00 \\
\hline [period trend] & $(0.64)$ & $(2.21)$ & $(2.61)$ & $(2.90)$ & $(0.01)$ & $(0.01)$ & $(0.00)$ & $(0.00)$ \\
\hline Observations & 480 & 480 & 480 & 480 & 480 & 480 & 480 & 480 \\
\hline Wald test for order effect on C-treatment & 0.000 & 0.000 & 0.000 & 0.016 & 0.000 & 0.278 & 0.016 & 0.711 \\
\hline Wald test for order effect on NC-treatment & 0.000 & 0.000 & 0.000 & 0.000 & 0.000 & 0.000 & 0.000 & 0.001 \\
\hline
\end{tabular}

Note: All regressions are estimated using a random effects error structure with the individual subject effects. In each regression we also include

dummy variables (not shown in the table) to control for session effects. Standard errors are in parentheses. Significance levels are: * significant at $10 \% ; * *$ significant at $5 \%$; *** significant at $1 \%$.

Table 6: Summary of Average Expected Amount Sent and Percentage Difference

\begin{tabular}{|c|c|c|c|c|c|c|}
\hline \multirow{2}{*}{ Decision } & \multicolumn{2}{|c|}{$\begin{array}{c}\text { Expected Amount } \\
\text { Sent }\end{array}$} & \multicolumn{2}{|c|}{$\begin{array}{l}\text { Actual Amount } \\
\text { Sent }\end{array}$} & \multicolumn{2}{|c|}{$\begin{array}{l}\text { Percentage Difference } \\
\text { From Actual Decisions }\end{array}$} \\
\hline & NC & $\mathrm{C}$ & $\mathrm{NC}$ & $\mathrm{C}$ & $\mathrm{NC}$ & $\mathrm{C}$ \\
\hline $\mathrm{P} 2$ to $\mathrm{P} 3$ & 80 & 233 & 96 & 231 & $16.8 \%$ & $0.9 \%$ \\
\hline $\mathrm{P} 3$ to $\mathrm{P} 2$ & 71 & 251 & 57 & 247 & $24.6 \%$ & $1.6 \%$ \\
\hline $\mathrm{P} 3$ to $\mathrm{P} 1$ & 60 & 191 & 35 & 136 & $71.4 \%$ & $40.4 \%$ \\
\hline
\end{tabular}


Table 7: Coding Table, Reliability Indexes, and Frequency of Coding

\begin{tabular}{|c|c|c|c|}
\hline Code & Description & $\begin{array}{l}\text { Cohen's } \\
\text { Kappa } K\end{array}$ & $\begin{array}{l}\text { Frequency } \\
\text { of coding }\end{array}$ \\
\hline & Messages sent by player 2 & & \\
\hline $1 \mathrm{a}$ & $\mathrm{P} 2$ proposed to send nothing to $\mathrm{P} 1$ and (almost) equal split between $\mathrm{P} 2$ and $\mathrm{P} 3$ & 0.53 & $21.7 \%$ \\
\hline $1 b$ & $\mathrm{P} 2$ proposed (almost) equal split between $\mathrm{P} 1, \mathrm{P} 2$ and $\mathrm{P} 3$ & 0.75 & $20.4 \%$ \\
\hline $1 \mathrm{c}$ & $\mathrm{P} 2$ proposed to send some to $\mathrm{P} 1$ and (almost) equal split between $\mathrm{P} 2$ and $\mathrm{P} 3$ & 0.81 & $0.4 \%$ \\
\hline $1 d$ & P2 made a positive comment or showed concern for well-being of P1 & 0.76 & $3.8 \%$ \\
\hline 1e & $\mathrm{P} 2$ made a negative comment about $\mathrm{P} 1$ & 0.50 & $7.1 \%$ \\
\hline 1f & $\mathrm{P} 2$ made any promises or showed trust in $\mathrm{P} 3$ & 0.39 & $4.6 \%$ \\
\hline $1 \mathrm{~g}$ & P2 used threat & 0.39 & $1.3 \%$ \\
\hline \multirow[t]{2}{*}{$1 \mathrm{~h}$} & $\mathrm{P} 2$ pleaded or appealed to $\mathrm{P} 3$ & 0.53 & $10.8 \%$ \\
\hline & Messages sent by player 3 & & \\
\hline $2 \mathrm{a}$ & $\mathrm{P} 3$ proposed to send nothing to $\mathrm{P} 1$ and (almost) equal split between $\mathrm{P} 2$ and $\mathrm{P} 3$ & 0.74 & $32.5 \%$ \\
\hline $2 b$ & $\mathrm{P} 3$ proposed (almost) equal split between $\mathrm{P} 1, \mathrm{P} 2$ and $\mathrm{P} 3$ & 0.77 & $24.6 \%$ \\
\hline $2 \mathrm{c}$ & $\mathrm{P} 3$ proposed to send some to $\mathrm{P} 1$ and (almost) equal split between $\mathrm{P} 2$ and $\mathrm{P} 3$ & 0.77 & $1.7 \%$ \\
\hline $2 d$ & P3 made a positive comment or showed concern for well-being of P1 & 0.50 & $5.8 \%$ \\
\hline $2 \mathrm{e}$ & $\mathrm{P} 3$ made a negative comment about $\mathrm{P} 1$ & 0.49 & $6.3 \%$ \\
\hline $2 f$ & P3 made any promises or showed trustworthiness & 0.72 & $9.6 \%$ \\
\hline \multirow[t]{2}{*}{$2 \mathrm{~g}$} & P3 mentioned about his or her good qualities & 0.32 & $0.8 \%$ \\
\hline & Messages indicating agreement or disagreement between players 2 and 3 & & \\
\hline $3 a$ & Agreement was reached on the first proposal & 0.70 & $69.2 \%$ \\
\hline $3 b$ & Agreement was reached on a different proposal than the first proposal & 0.67 & $22.9 \%$ \\
\hline $3 \mathrm{c}$ & Agreement was not reached & N/A & $0.0 \%$ \\
\hline
\end{tabular}


Table 8: Multilevel Mixed-effects Regression on Categories of Messages

\begin{tabular}{|c|c|c|c|c|c|c|c|}
\hline \multicolumn{2}{|c|}{ Regression } & (1) & $(2)$ & (3) & (4) & $(5)$ & (6) \\
\hline \multirow{2}{*}{\multicolumn{2}{|c|}{ Dependent variable }} & \multicolumn{3}{|c|}{ Amount Sent } & \multicolumn{3}{|c|}{ Amount sent Relative to Income } \\
\hline & & P2 to P3 & $\mathrm{P} 3$ to $\mathrm{P} 2$ & P3 to P1 & $\mathrm{P} 2$ to $\mathrm{P} 3$ & $\mathrm{P} 3$ to $\mathrm{P} 2$ & $\mathrm{P} 3$ to $\mathrm{P} 1$ \\
\hline \multicolumn{8}{|c|}{ Only one player made a proposal } \\
\hline $1 \mathrm{a}$ & $\mathrm{P} 2$ proposed to send nothing to $\mathrm{P} 1$ and (almost) equal split between $\mathrm{P} 2$ and $\mathrm{P} 3$ & $\begin{array}{c}-2.37 \\
(37.13)\end{array}$ & $\begin{array}{c}42.48 \\
(55.22)\end{array}$ & $\begin{array}{l}-124.17 * * * \\
\quad(39.64)\end{array}$ & $\begin{array}{c}0.07 \\
(0.08)\end{array}$ & $\begin{array}{l}0.11 * * \\
(0.05)\end{array}$ & $\begin{array}{l}-0.13 * * * \\
(0.03)\end{array}$ \\
\hline $1 b$ & $\mathrm{P} 2$ proposed (almost) equal split between $\mathrm{P} 1, \mathrm{P} 2$ and $\mathrm{P} 3$ & $\begin{array}{c}109.46^{* *} \\
(44.19)\end{array}$ & $\begin{array}{c}141.29 * * \\
(65.76)\end{array}$ & $\begin{array}{c}150.30 * * * \\
(48.03)\end{array}$ & $\begin{array}{c}0.14 \\
(0.10)\end{array}$ & $\begin{array}{c}0.05 \\
(0.06)\end{array}$ & $\begin{array}{c}0.10 * * \\
(0.04)\end{array}$ \\
\hline $2 \mathrm{a}$ & $\mathrm{P} 3$ proposed to send nothing to $\mathrm{P} 1$ and (almost) equal split between $\mathrm{P} 2$ and $\mathrm{P} 3$ & $\begin{array}{l}-16.89 \\
(29.01)\end{array}$ & $\begin{array}{l}-42.50 \\
(43.57)\end{array}$ & $\begin{array}{c}-142.32 * * * \\
(31.67)\end{array}$ & $\begin{array}{l}0.12 * \\
(0.06)\end{array}$ & $\begin{array}{c}0.05 \\
(0.04)\end{array}$ & $\begin{array}{c}-0.15 * * * \\
(0.03)\end{array}$ \\
\hline \multirow[t]{2}{*}{$2 b$} & $\mathrm{P} 3$ proposed (almost) equal split between $\mathrm{P} 1, \mathrm{P} 2$ and $\mathrm{P} 3$ & $\begin{array}{l}133.98 * * * \\
(29.87)\end{array}$ & $\begin{array}{c}65.21 \\
(45.17) \\
\end{array}$ & $\begin{array}{l}139.74 * * * \\
(33.06)\end{array}$ & $\begin{array}{l}0.16^{* *} \\
(0.06)\end{array}$ & $\begin{array}{l}-0.06 \\
(0.04)\end{array}$ & $\begin{array}{c}0.10 * * * \\
(0.03)\end{array}$ \\
\hline & The same proposal made by players 2 and 3 & & & & & & \\
\hline $1 \mathrm{a}+2 \mathrm{a}$ & $\begin{array}{l}\text { Both P2 and P3 proposed to send nothing to P1 and (almost) equal split } \\
\text { between P2 and P3 }\end{array}$ & $\begin{array}{l}66.34 * \\
(35.07)\end{array}$ & $\begin{array}{c}-0.78 \\
(56.56)\end{array}$ & $\begin{array}{c}-126.98 * * * \\
(39.87)\end{array}$ & $\begin{array}{c}0.27 * * * \\
(0.08)\end{array}$ & $\begin{array}{c}0.06 \\
(0.05)\end{array}$ & $\begin{array}{c}-0.15 * * * \\
(0.03)\end{array}$ \\
\hline \multirow[t]{2}{*}{$1 b+2 b$} & Both P2 and P3 proposed (almost) equal split between P1, P2 and P3 & $\begin{array}{c}173.87 * * * \\
(57.67) \\
\end{array}$ & $\begin{array}{c}149.93 * \\
(81.90) \\
\end{array}$ & $\begin{array}{c}246.40 * * * \\
(59.79)\end{array}$ & $\begin{array}{l}0.23 * \\
(0.12) \\
\end{array}$ & $\begin{array}{c}0.00 \\
(0.07) \\
\end{array}$ & $\begin{array}{c}0.11^{* *} \\
(0.05) \\
\end{array}$ \\
\hline & Two different proposals made by players 2 and 3 & & & & & & \\
\hline $1 \mathrm{a}+2 \mathrm{~b}$ & $\begin{array}{l}\mathrm{P} 2 \text { proposed to send nothing to } \mathrm{P} 1 \text { and (almost) equal split between } \mathrm{P} 2 \text { and } \mathrm{P} 3 \\
\text { while } \mathrm{P} 3 \text { proposed (almost) equal split between } \mathrm{P} 1, \mathrm{P} 2 \text { and } \mathrm{P} 3\end{array}$ & $\begin{array}{c}61.12 \\
(51.56)\end{array}$ & $\begin{array}{c}35.90 \\
(79.20)\end{array}$ & $\begin{array}{c}31.41 \\
(58.36)\end{array}$ & $\begin{array}{c}0.09 \\
(0.11)\end{array}$ & $\begin{array}{l}-0.05 \\
(0.07)\end{array}$ & $\begin{array}{l}0.11 * * \\
(0.05)\end{array}$ \\
\hline \multirow[t]{2}{*}{$1 b+2 a$} & $\begin{array}{l}\mathrm{P} 3 \text { proposed to send nothing to } \mathrm{P} 1 \text { and (almost) equal split between } \mathrm{P} 2 \text { and } \mathrm{P} 3 \\
\text { while } \mathrm{P} 2 \text { proposed (almost) equal split between } \mathrm{P} 1, \mathrm{P} 2 \text { and } \mathrm{P} 3\end{array}$ & $\begin{array}{c}85.11 \\
(67.07)\end{array}$ & $\begin{array}{l}117.72 \\
(97.58)\end{array}$ & $\begin{array}{l}211.53 * * * \\
(72.88)\end{array}$ & $\begin{array}{l}-0.06 \\
(0.15)\end{array}$ & $\begin{array}{l}-0.03 \\
(0.08)\end{array}$ & $\begin{array}{c}0.13 * * \\
(0.06)\end{array}$ \\
\hline & The most frequently used messages & & & & & & \\
\hline $1 \mathrm{~h}$ & $\mathrm{P} 2$ pleaded or appealed to $\mathrm{P} 3$ & $\begin{array}{c}67.17 \\
(50.44)\end{array}$ & $\begin{array}{c}56.99 \\
(76.70)\end{array}$ & $\begin{array}{c}4.68 \\
(55.92)\end{array}$ & $\begin{array}{l}0.21 * \\
(0.11)\end{array}$ & $\begin{array}{c}0.04 \\
(0.07)\end{array}$ & $\begin{array}{c}0.01 \\
(0.05)\end{array}$ \\
\hline \multirow[t]{4}{*}{$2 \mathrm{f}$} & P3 made any promises or showed trustworthiness & $\begin{array}{c}25.51 \\
(35.21)\end{array}$ & $\begin{array}{c}71.86 \\
(51.97)\end{array}$ & $\begin{array}{c}33.61 \\
(36.53)\end{array}$ & $\begin{array}{c}0.07 \\
(0.07)\end{array}$ & $\begin{array}{c}0.00 \\
(0.05)\end{array}$ & $\begin{array}{c}0.00 \\
(0.03)\end{array}$ \\
\hline & $\begin{array}{l}\text { Period } \\
\quad \text { [period trend] }\end{array}$ & $\begin{array}{c}6.98 \\
(4.49)\end{array}$ & $\begin{array}{c}8.47 \\
(7.53)\end{array}$ & $\begin{array}{c}2.63 \\
(4.51)\end{array}$ & $\begin{array}{c}0.01 \\
(0.01)\end{array}$ & $\begin{array}{c}0.00 \\
(0.01)\end{array}$ & $\begin{array}{l}-0.00 \\
(0.00)\end{array}$ \\
\hline & Constant & $\begin{array}{c}129.78 * * * \\
(36.25) \\
\end{array}$ & $\begin{array}{c}153.63 * * * \\
(54.68) \\
\end{array}$ & $\begin{array}{c}134.59 * * * \\
(32.57)\end{array}$ & $\begin{array}{c}0.59 * * * \\
(0.09)\end{array}$ & $\begin{array}{c}0.25 * * * \\
(0.06)\end{array}$ & $\begin{array}{c}0.18 * * * \\
(0.03)\end{array}$ \\
\hline & Observations & 120 & 120 & 120 & 120 & 120 & 120 \\
\hline
\end{tabular}

Note: Standard errors are in parentheses. Significance levels are: * significant at 10\%;** significant at 5\%; *** significant at $1 \%$. 
Figure 1: Distribution of Return Ratio in the NC and C Treatments

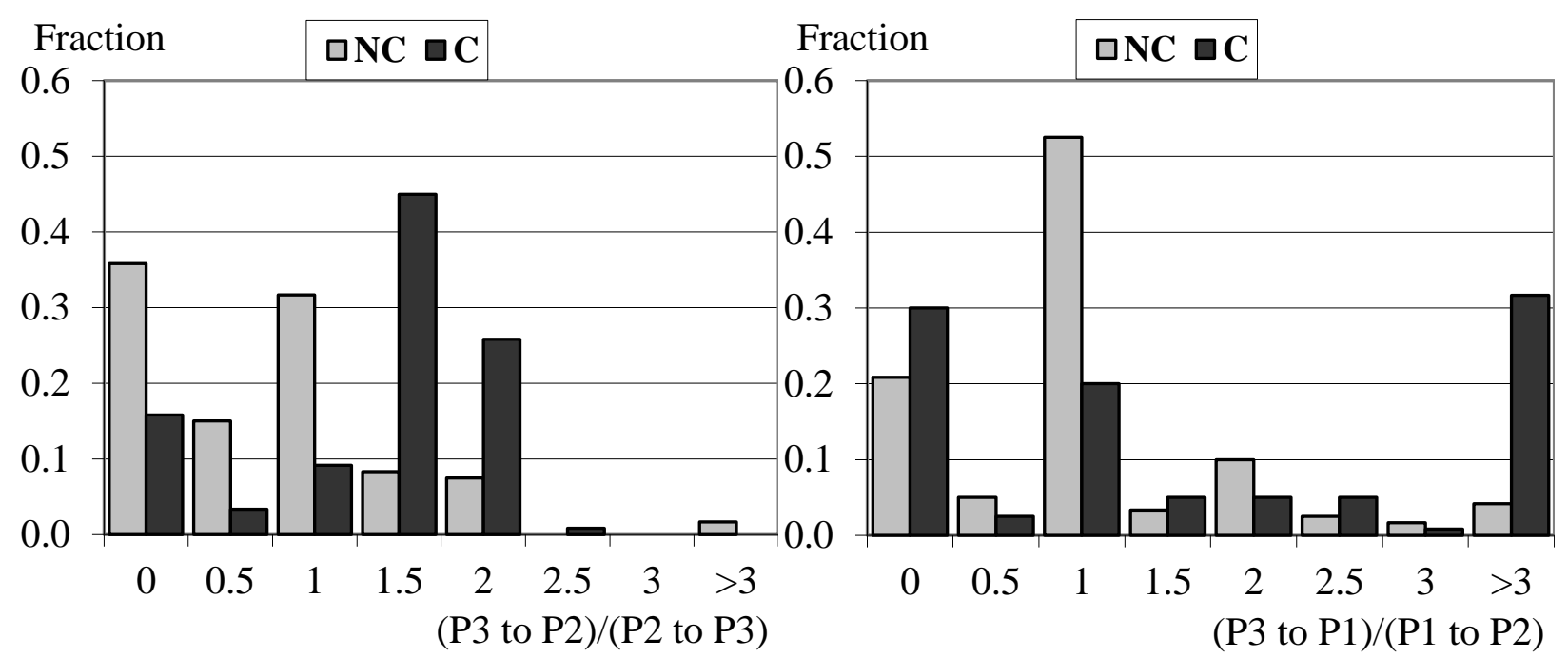


Figure 2a: Average Amount Sent Over the Periods in C-NC Sessions

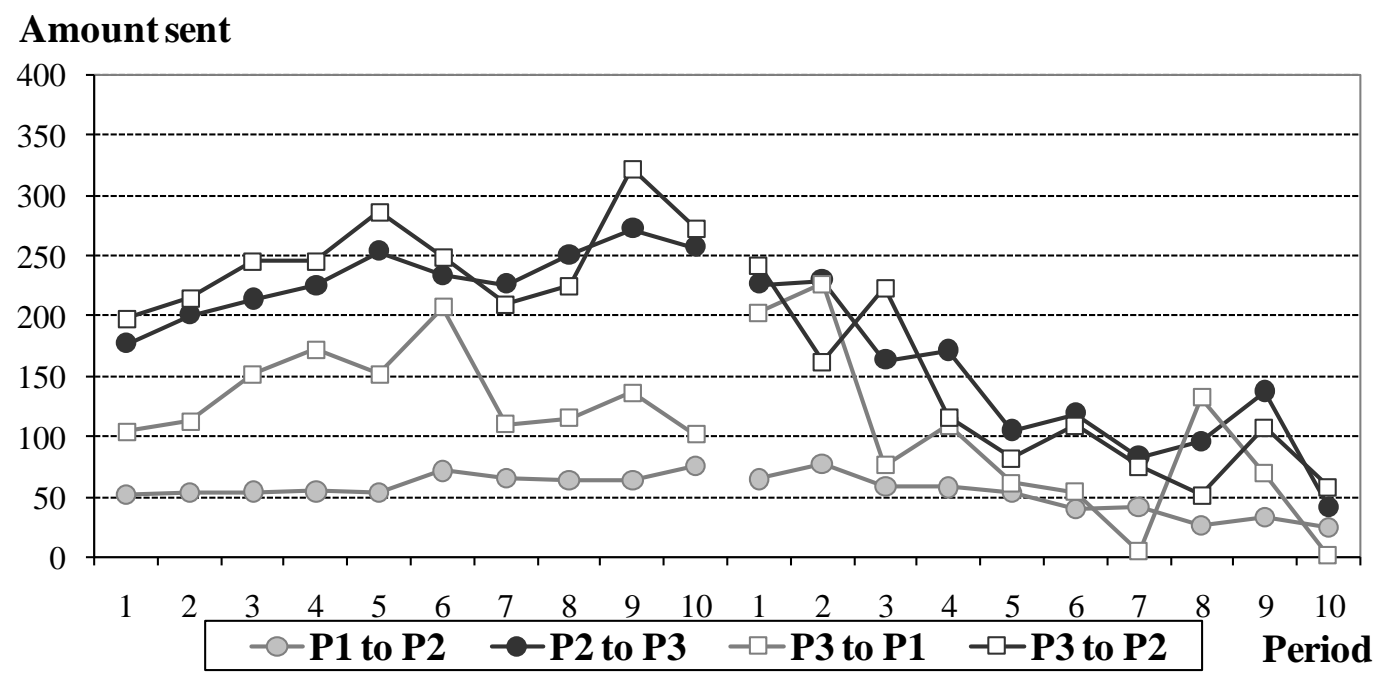

Figure 2b: Average Amount Sent Over the Periods in NC-C Sessions

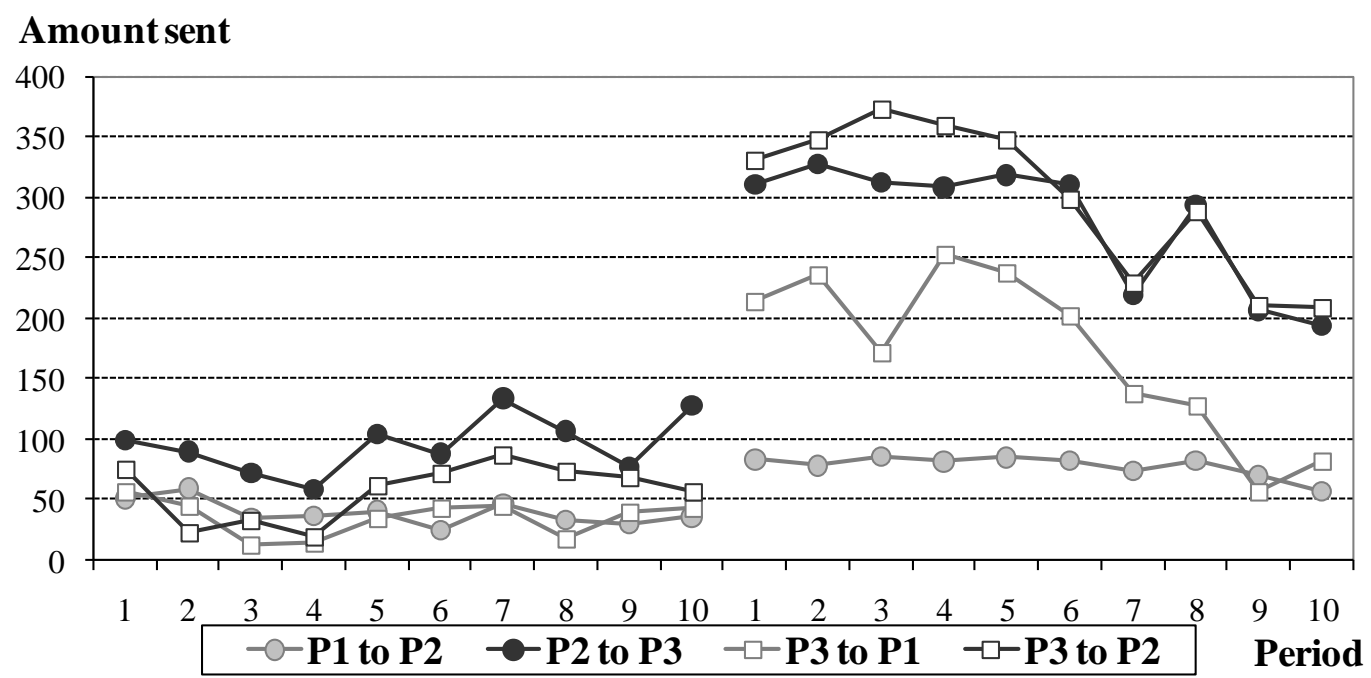




\section{Appendix I (For Online Publication) - The Instructions for the NC-C Session}

\section{INSTRUCTIONS}

This is an experiment in the economics of multi-person strategic decision making. Various research agencies have provided funds for this research. The instructions are simple. If you follow them closely and make appropriate decisions, you can earn an appreciable amount of money. The currency used in the experiment is francs. Francs will be converted to U.S. Dollars at a rate of $\mathbf{1 0 0}$ francs to one dollar. At the end of today's experiment, you will be paid in private and in cash. $\underline{\mathbf{2 4}}$ participants are in today's experiment.

It is very important that you remain silent and do not look at other people's work. If you have any questions, or need assistance of any kind, please raise your hand and an experimenter will come to you. If you talk, laugh, exclaim out loud, etc., you will be asked to leave and you will not be paid. We expect and appreciate your cooperation.

The experiment is composed of 2 parts. Each part consists of 10 decision making periods. At this time we proceed to Part 1 of the experiment.

\section{INSTRUCTIONS FOR PART 1}

The first part of the experiment consists of $\mathbf{1 0}$ decision-making periods. The $\mathbf{2 4}$ participants will be randomly assigned into $\mathbf{8}$ three-person groups. In addition to the group assignment each participant will also be randomly assigned to a specific type in the group, designated as Person 1, Person 2, and Person 3. You will remain in the same type throughout the experiment. At the beginning of each period you will be randomly re-grouped with two other participants to form a three-person group, with one person of each type in each group.

The following diagram shows how this part of the experiment proceeds:

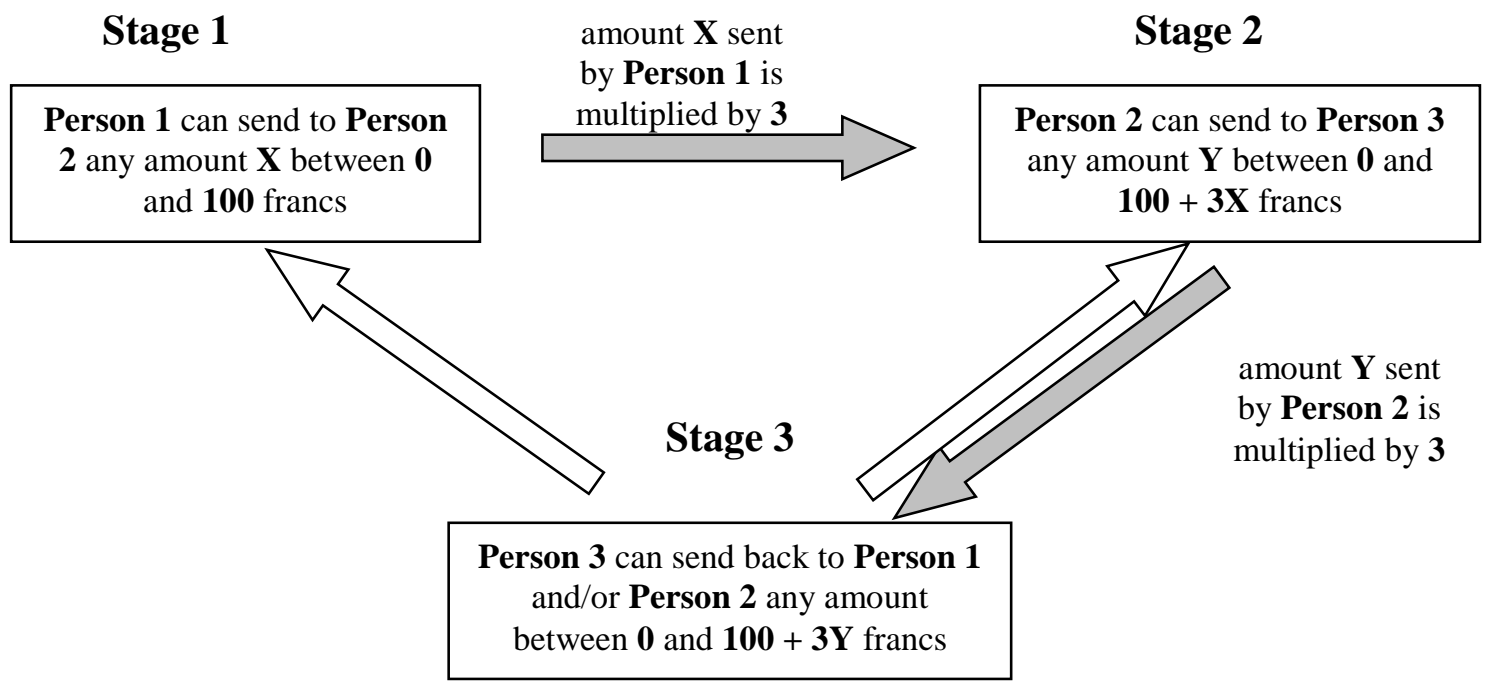

During each period, you and the other two participants in your group will make choices which will determine your payoffs. Each period is comprised of three stages. At Stage 1 Person 1 can send to Person 2 any amount $X$ between 0 and 100 francs. Amount $X$ sent by Person 1 is multiplied by 3. At Stage 2 Person 2 can send to Person 3 any amount $Y$ between 0 and $100+$ 
$3 X$ francs. Amount $Y$ sent by Person 2 is multiplied by 3 . At Stage 3 Person 3 can send back to Person 1 and/or Person 2 any amount between 0 and $100+3 Y$ francs.

More specifically, Person 1, 2 and 3 are given the initial of $\mathbf{1 0 0}$ francs in their individual accounts. At Stage 1 Person 1 makes a decision how many francs to send to Person $\mathbf{2}$ and how many francs to allocate to his or her individual account, as shown on the screen below.

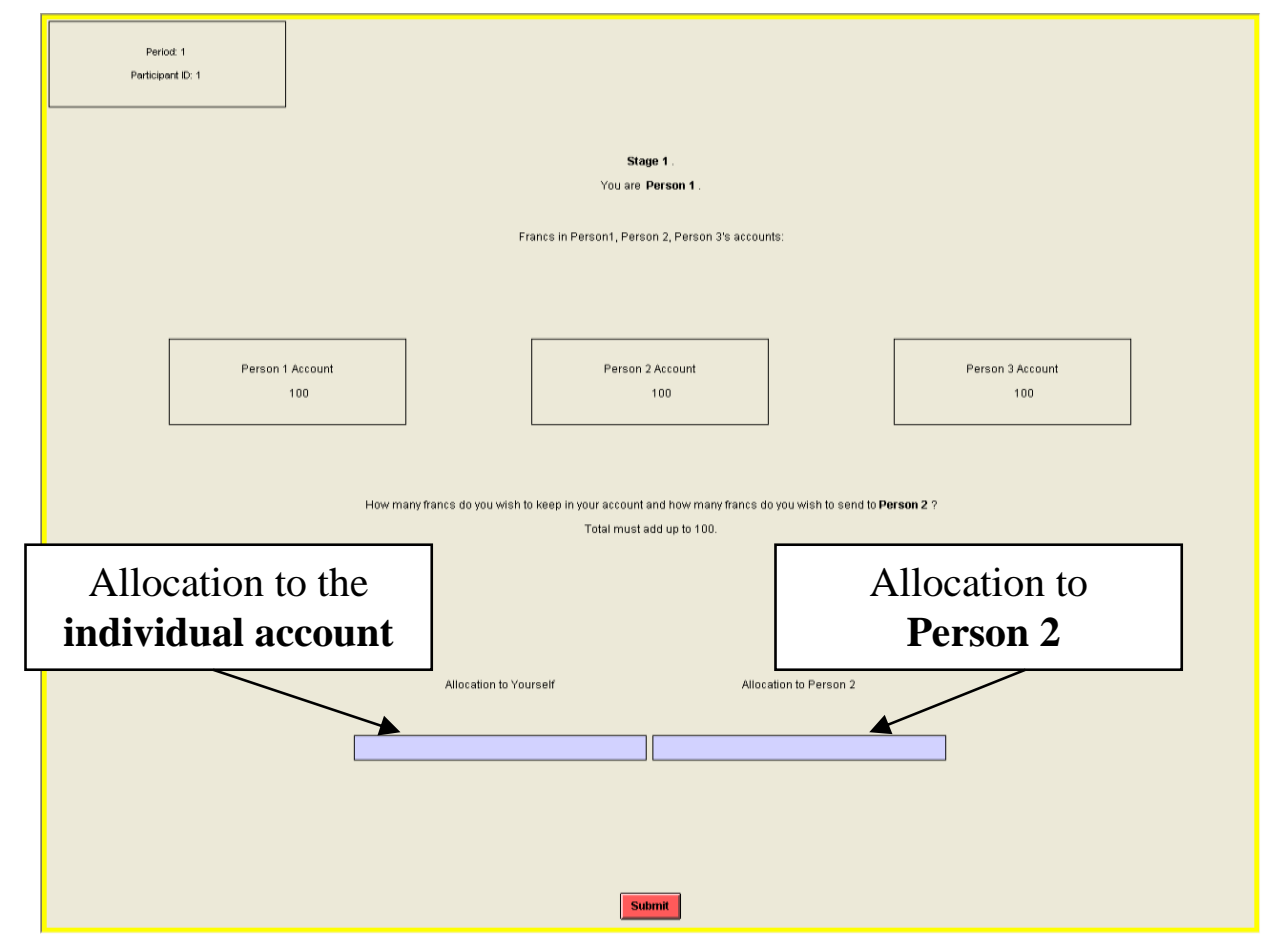

Decision Screen for Person 1 at Stage 1

Person 1 has the opportunity to send any number of francs between $\mathbf{0}$ and $\mathbf{1 0 0}$ to Person 2's account. Each franc sent by Person 1 is multiplied by $\mathbf{3}$. For example, if Person 1 sends 40 francs to Person 2, the amount received by Person 2 is 120 francs $(40 \times 3=120)$. At the end of Stage 1 Person 2 and 3 learn the decision made by Person 1 and the total amount of francs in all three individual accounts.

At Stage 2 Person 2 will then decide how many francs to send to Person 3 and how many francs to allocate to his or her individual account. Person 2 can send any amount of francs available in his/her account at that time. Each franc sent by Person 2 is multiplied by $\mathbf{3}$. For example, if Person 2 sends 60 francs, the amount received by Person 3 is 180 francs $(60 \times 3=180)$. At the end of Stage 2 Person 3 and 1 learn the decisions made by Person 2 and the total amount of francs in all three individual accounts. 
The decision screen for Person 2 is as following:

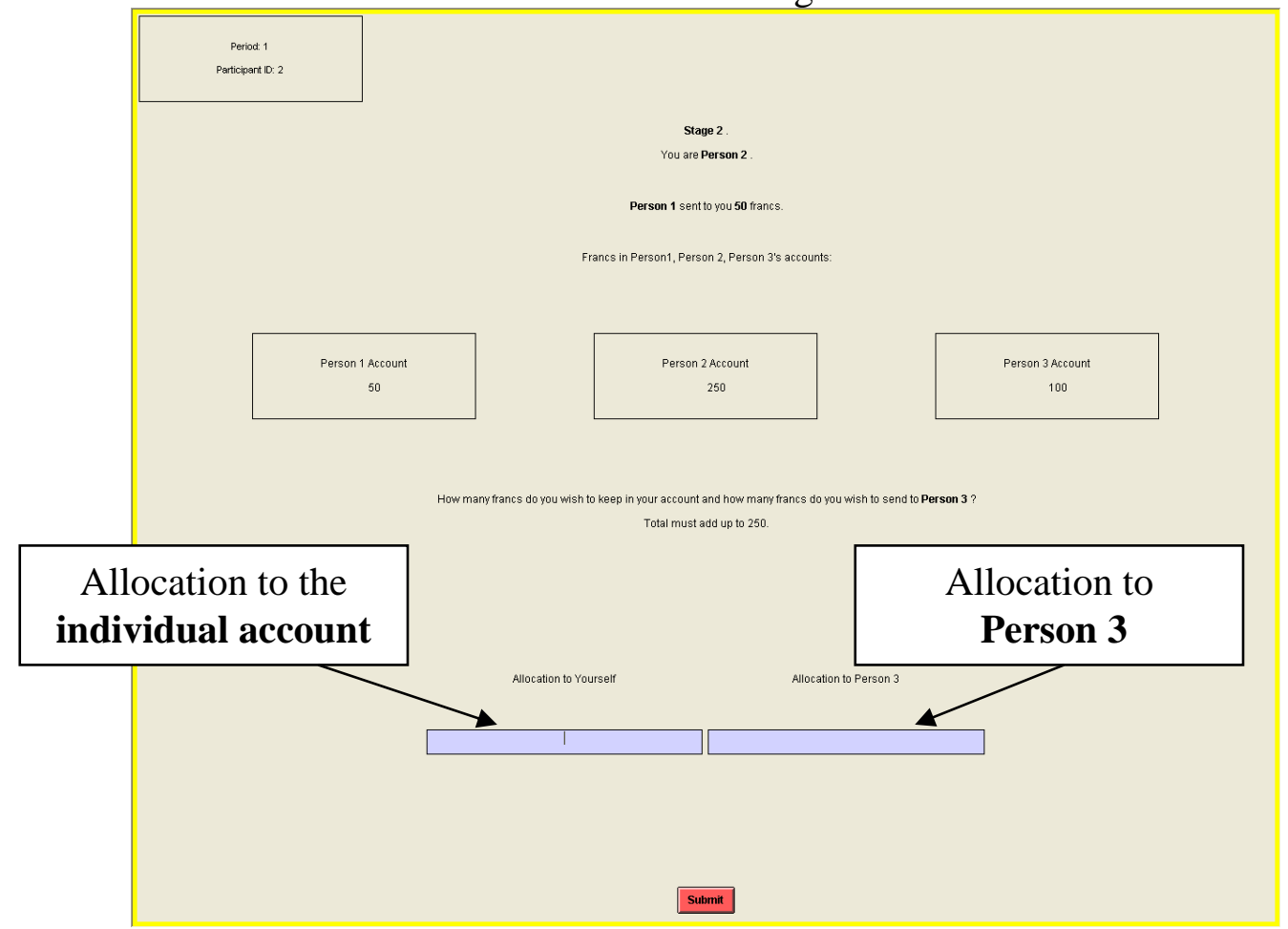

Decision Screen for Person 2 at Stage 2

At Stage 3 Person 3 will then decide how many francs to send back to Person 1, how many francs to send back to Person 2, and how many francs to allocate to his or her individual account as shown in the following screen:

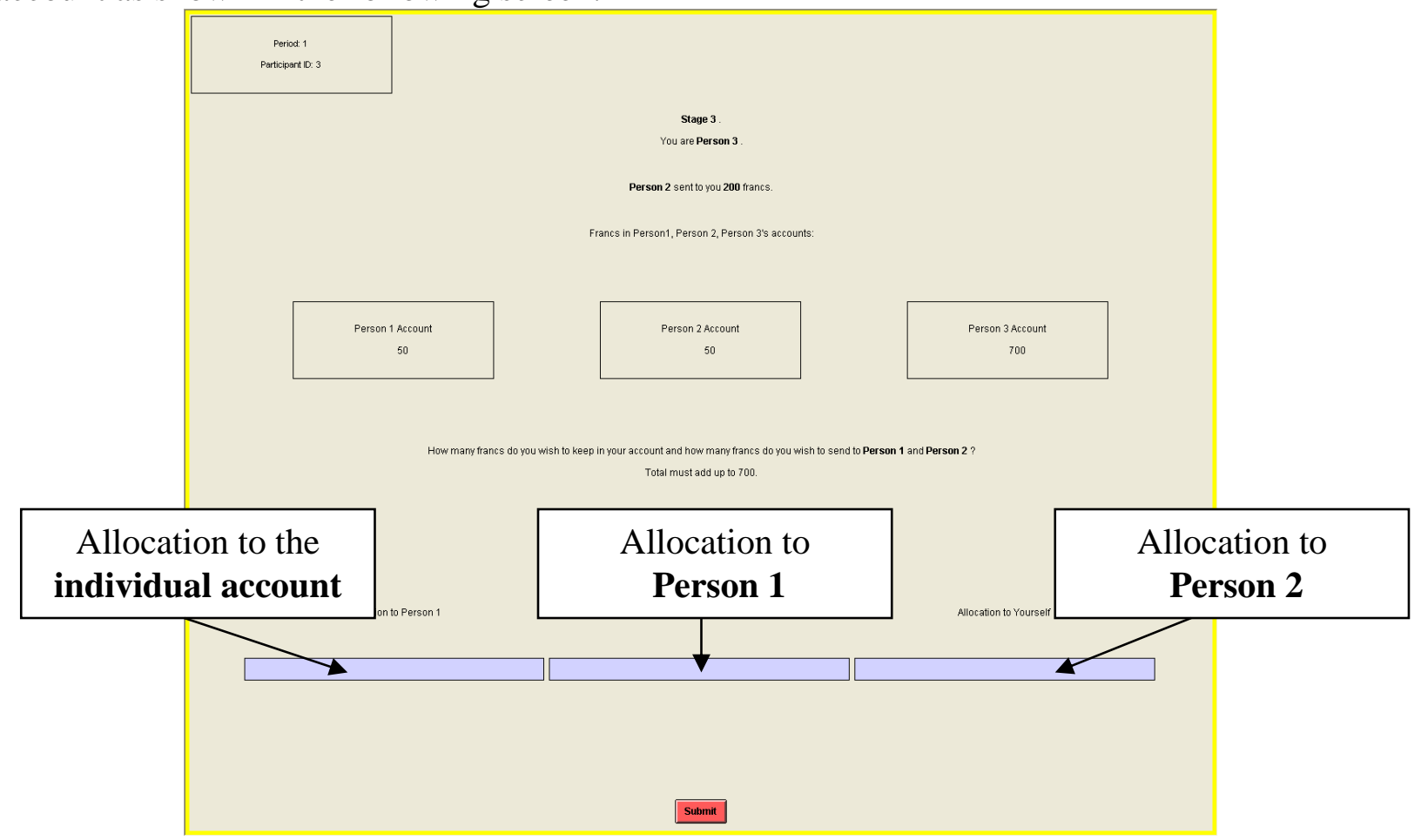

Decision Screen for Person 3 
Finally, at the end of the Stage 3 the total period earnings and the decisions of all three participants in the group made at each stage are reported to each person as shown in the outcome screen below:

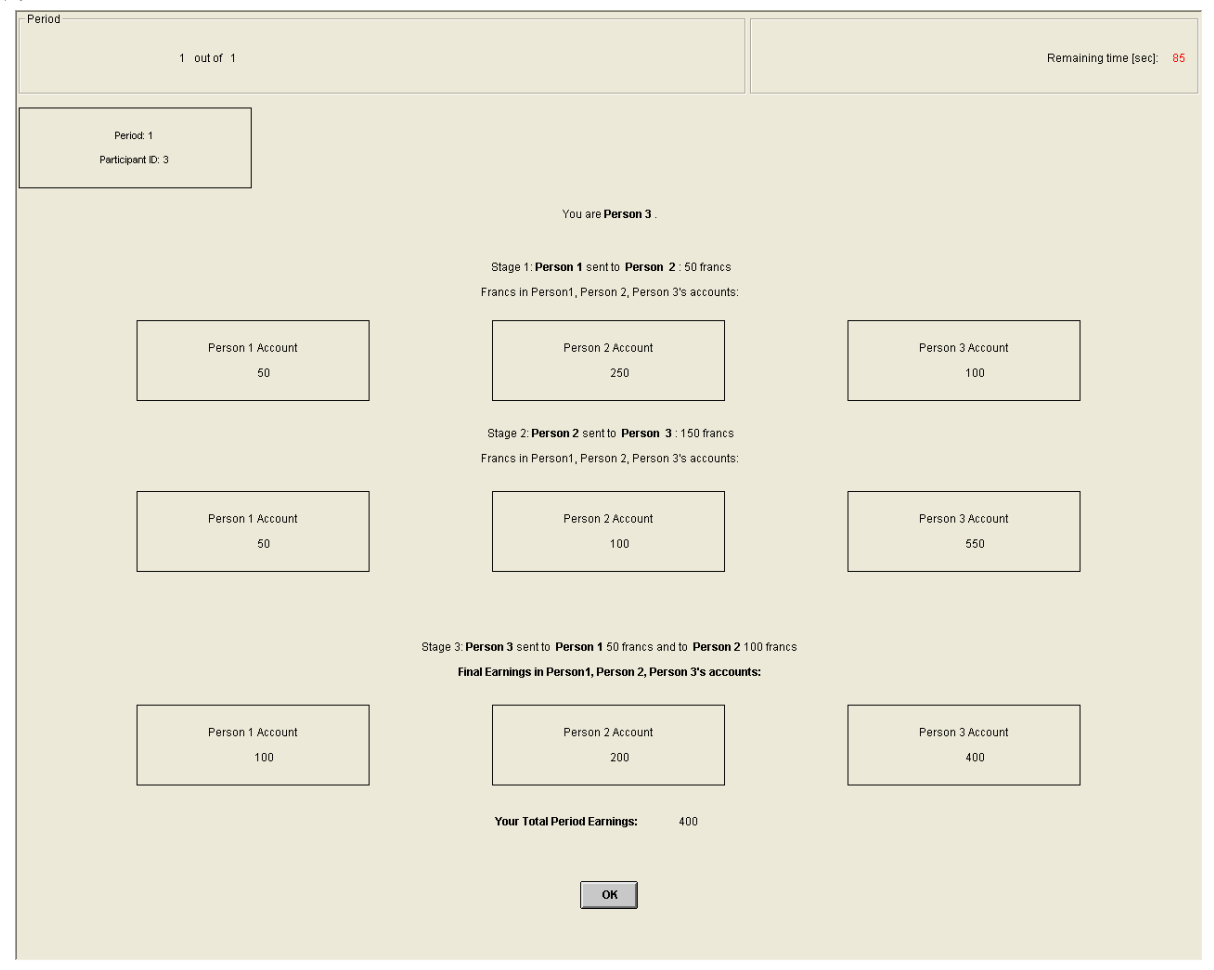

\section{Outcome Screen}

Once the outcome screen is displayed, please record your results for the period on your record sheet under the appropriate heading.

\section{IMPORTANT NOTES}

You will not be told which of the participants in this room are assigned to which group. All three Persons in the group have the opportunity to send some, all, or none of the francs available to them. You will remain in the same role throughout the experiment. At the beginning of each period you will be randomly re-grouped with two other participants to from a threeperson group, with one person of each type in each group.

At the end of the experiment we will randomly choose 2 of the $\mathbf{1 0}$ periods for actual payment in Part 1 using dice roll (ten-sided die with numbers from 1 to 10). You will sum the total earnings for these 2 periods and convert them to a U.S. dollar payment, as shown on the last page of your record sheet.

\section{Are there any questions?}

\section{PREDICTIONS BY PERSON 1 (This part of the instructions was given only to person 1)}

You are assigned to be Person 1. After you make your decision in Stage 1, you will be asked to enter three predictions in Stage 2: prediction about how many francs will Person 2 send 
to Person 3, prediction about how many francs will Person 3 send back to Person 2, and prediction about how many francs will Person 3 send back to you. In addition to your earnings from the individual account you will be paid for the number of correct predictions you make. In particular, at the end of the period, we will look at the choices actually made by Person 2 and 3 you are paired with and compare their choices to your predictions. You will be paid $\mathbf{1 0}$ francs for each prediction if your prediction differs by no more than 5 percent from the actual decision made. If your prediction differs by more than 5 percent from the actual decision made, you will receive $\mathbf{0}$ francs for that prediction.

The decision screen for prediction is as following:

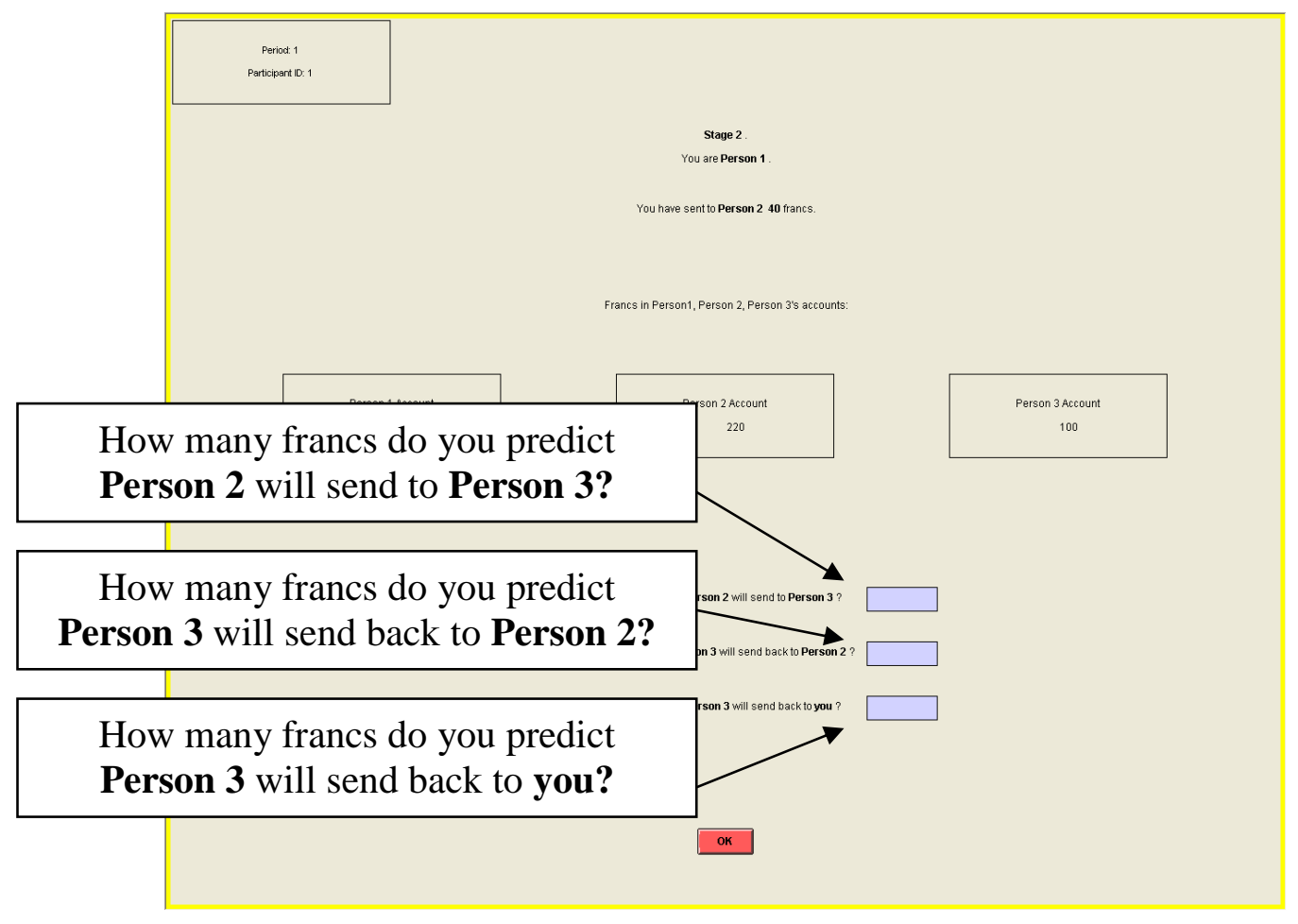

Note that since your prediction is made before you know what actual decisions are made by Person 2 and Person 3 you are paired with, you maximize the expected size of your prediction payoff by simply stating your true beliefs about what you think Person 2 and Person 3 will do. Any other prediction will decrease the amount you can expect to earn from your prediction payoff.

\section{INSTRUCTIONS FOR PART 2}

The second part of the experiment consists of $\mathbf{1 0}$ decision-making periods. The rules for Part 2 are exactly the same as the rules for Part 1.

The only difference is that in this part of the experiment, after Stage 1, Person 2 and Person 3 will have an opportunity to communicate with each other in a chat window. The communication will take place only after Person 2 and 3 have learned the decision made by Person 1. Person 2 and 3 will have 90 seconds to chat with each other anonymously. Although we will record the messages, only Person 2 and 3 will see them. Note, in sending messages back and forth we request that you follow two simple rules: (1) Be civil to each other and use no profanity and (2) Do not identify yourself. 
After the chat period is over, at Stage 2 Person 2 will decide how many francs to send to Person 3 and how many francs to allocate to his or her individual account. At the end of Stage 2 Person 3 and 1 learn the decisions made by Person 2 and the total amount of francs in all three individual accounts.

At Stage 3 Person 3 will then decide how many francs to send back to Person 1, how many francs to send back to Person 2, and how many francs to allocate to his or her individual account.

Finally, at the end of the Stage 3 the earnings for all three participants in the group are reported to each person. Please record your results for the period on your record sheet under the appropriate heading.

\section{IMPORTANT NOTES}

You will not be told which of the participants in this room are assigned to which group. All three Persons in the group have the opportunity to send some, all, or none of the francs available to them. You will remain in the same role throughout the experiment. At the beginning of each period you will be randomly re-grouped with two other participants to from a threeperson group, with one person of each type in each group.

At the end of the experiment we will randomly choose $\mathbf{2}$ of the $\mathbf{1 0}$ periods for actual payment in Part 2 using dice roll (ten-sided die with numbers from 1 to 10). You will sum the total earnings for these 2 periods and convert them to a U.S. dollar payment, as shown on the last page of your record sheet.

\section{Are there any questions?}




\section{Appendix II (For Online Publication) - Instructions for Coders}

\section{Coding Instructions}

Purpose: To study how communication affects the play of the game.

Game: Refer to the attached instructions for the experiment.

\section{Coding Rules:}

(1) The unit of observation is all messages in a given period. You should not start to code until you finish reading all messages in a given period. It is very important to look at the context of the messages across lines to properly interpret and code them.

(2) If a unit of observation is deemed to contain the relevant category of content, enter the code for the category in the relevant column beside the first line of the unit.

(3) Each unit can be coded under as many or few categories as you deem appropriate. Enter the additional codes in columns to the right.

(4) You should independently code all messages. Do not discuss with anyone about which statements should fall into which categories.

(5) Your job is to capture what had been said rather than why it was said or what effect it had. Think of yourself as a "coding machine."

(6) Code the sessions in the chronological order that the sessions were conducted, as explained and presented by your coding supervisor.

Please track the time you spend on coding the messages and training. You will be paid $\mathbf{\$ 1 2}$ for each hour working on this project.

Thanks a lot for your participation in the coding task! 
2013

\section{Economic Science Institute Working Papers}

13-02 McCarter, M. and Sheremeta, R. You Can't Put Old Wine in New Bottles: The Effect of Newcomers on Coordination in Groups.

13-01 Corgnet, B., Hernan-Gonzalez, R., and Rassenti, S. Peer Pressure and Moral Hazard in Teams: Experimental Evidence.

\section{2}

12-31 Thomas, C. An Alternating-Offers Model of Multilateral Negotiations.

12-30 Mago, S., Sheremeta, R. and Yates, A. Best-of-Three Contest Experiments: Strategic versus psychological momentum.

12-29 Bigoni, M., Camera, G. and Casari, M. Strategies of Cooperation and Punishment among Students and Clerical Workers.

12-28 Camera, G. and Kim, J. Buyer's Equilibrium with Capacity Constraints and Restricted Mobility: A recursive approach.

12-27 Camera, G., Casari, M., and Bigoni, M. Binding Promises and Cooperation Among Strangers.

12-26 Schniter, E., Shields, T. and Dickhaut, J. Ageism \& Cooperation.

12-25 Gjerstad, S. and Smith, V. Balance Sheet Crises: Causes, Consequences and Responses.

12-24 Gómez-Miñambres, J., Corgnet, B. and Hernán-Gonzalez, R. Goal Setting and Monetary Incentives: When Large Stakes Are Not Enough.

12-23 Clots-Figueras, I., Hernán González, R., and Kujal, P. Asymmetry and Deception in the Investment Game.

12-22 Dechenaux, E., Kovenock, D. and Sheremeta, R. A Survey of Experimental Research on Contests, All-Pay Auctions and Tournaments.

12-21 Rubin, J. and Sheremeta, R. Principal-Agent Settings with Random Shocks.

12-20 Gómez-Miñambres, J. and Schniter, E. Menu-Dependent Emotions and Self-Control.

12-19 Schniter, E., Sheremeta, R., and Sznycer, D. Building and Rebuilding Trust with Promises and Apologies. 
12-18 Shields, T. and Xin, B. Higher-order Beliefs in Simple Trading Models.

12-17 Pfeiffer, G. and Shields, T. Performance-Based Compensation and Firm Value: Experimental evidence.

12-16 Kimbrough, E. and Sheremeta, R. Why Can't We Be Friends? Entitlements, bargaining, and conflict.

12-15 Mago, S., Savikhin, A., and Sheremeta, R. Facing Your Opponents: Social identification and information feedback in contests.

12-14 McCarter, M., Kopelman, S., Turk, T. and Ybarra, C. Too Many Cooks Spoil the Broth: How the tragedy of the anticommons emerges in organizations.

12-13 Chowdhury, S., Sheremeta, R. and Turocy, T. Overdissipation and Convergence in Rent-seeking Experiments: Cost structure and prize allocation rules.

12-12 Bodsky, R., Donato, D., James, K. and Porter, D. Experimental Evidence on the Properties of the California's Cap and Trade Price Containment Reserve.

12-11 Branas-Garza, P., Espin, A. and Exadaktylos, F. Students, Volunteers and Subjects: Experiments on social preferences.

12-10 Klose, B. and Kovenock, D. Extremism Drives Out Moderation.

12-09 Buchanan, J. and Wilson, B. An Experiment on Protecting Intellectual Property.

12-08 Buchanan, J., Gjerstad, S. and Porter, D. Information Effects in Multi-Unit Dutch Auctions.

12-07 Price, C. and Sheremeta, R. Endowment Origin, Demographic Effects and Individual Preferences in Contests.

12-06 Magoa, S. and Sheremeta, R. Multi-Battle Contests: An experimental study.

12-05 Sheremeta, R. and Shields, T. Do Liars Believe? Beliefs and Other-Regarding Preferences in Sender-Receiver Games.

12-04 Sheremeta, R., Masters, W. and Cason. T. Winner-Take-All and Proportional-Prize Contests: Theory and experimental results.

12-03 Buchanan, J., Gjerstad, S. and Smith, V. There's No Place Like Home.

12-02 Corgnet, B. and Rodriguez-Lara, I. Are you a Good Employee or Simply a Good Guy? Influence $\underline{\text { Costs and Contract Design. }}$

12-01 Kimbrough, E. and Sheremeta, R. Side-Payments and the Costs of Conflict. 
11-20 Cason, T., Savikhin, A. and Sheremeta, R. Behavioral Spillovers in Coordination Games.

11-19 Munro, D. and Rassenti, S. Combinatorial Clock Auctions: Price direction and performance.

11-18 Schniter, E., Sheremeta, R., and Sznycer, D. Restoring Damaged Trust with Promises, Atonement and Apology.

11-17 Brañas-Garza, P., and Proestakis, A. Self-discrimination: A field experiment on obesity.

11-16 Brañas-Garza, P., Bucheli, M., Paz Espinosa, M., and García-Muñoz, T. Moral Cleansing and Moral Licenses: Experimental evidence.

11-15 Caginalp, G., Porter, D., and Hao, L. Asset Market Reactions to News: An experimental study.

11-14 Benito, J., Branas-Garz, P., Penelope Hernandez, P., and Sanchis Llopis, J. Strategic Behavior in Schelling Dynamics: A new result and experimental evidence.

11-13 Chui, M., Porter, D., Rassenti, S. and Smith, V. The Effect of Bidding Information in Ascending Auctions.

11-12 Schniter, E., Sheremeta, R. and Shields, T. Conflicted Minds: Recalibrational emotions following trust-based interaction.

11-11 Pedro Rey-Biel, P., Sheremeta, R. and Uler, N. (Bad) Luck or (Lack of) Effort?: Comparing social sharing norms between US and Europe.

11-10 Deck, C., Porter, D., and Smith, V. Double Bubbles in Assets Markets with Multiple Generations.

11-09 Kimbrough, E., Sheremeta, R., and Shields, T. Resolving Conflicts by a Random Device.

11-08 Brañas-Garza, P., García-Muñoz, T., and Hernan, R. Cognitive effort in the Beauty Contest Game.

11-07 Grether, D., Porter, D., and Shum, M. Intimidation or Impatience? Jump Bidding in On-line Ascending Automobile Auctions.

11-06 Rietz, T., Schniter, E., Sheremeta, R., and Shields, T. Trust, Reciprocity and Rules.

11-05 Corgnet, B., Hernan-Gonzalez, R., and Rassenti, S. Real Effort, Real Leisure and Real-time Supervision: Incentives and peer pressure in virtual organizations.

11-04 Corgnet, B. and Hernán-González R. Don’t Ask Me If You Will Not Listen: The dilemma of participative decision making.

11-03 Rietz, T., Sheremeta, R., Shields, T., and Smith, V. Transparency, Efficiency and the Distribution of Economic Welfare in Pass-Through Investment Trust Games.

11-02 Corgnet, B., Kujal, P. and Porter, D. The Effect of Reliability, Content and Timing of Public Announcements on Asset Trading Behavior. 
11-01 Corgnet, B., Kujal, P. and Porter, D. Reaction to Public Information in Markets: How much does ambiguity matter?

\section{0}

10-23 Sheremeta, R. Perfect-Substitutes, Best-Shot, and Weakest-Link Contests between Groups.

10-22 Mago, S., Sheremeta, R., and Yates, A. Best-of-Three Contests: Experimental evidence.

10-21 Kimbrough, E. and Sheremeta, R. Make Him an Offer He Can't Refuse: Avoiding conflicts through side payments.

10-20 Savikhim, A. and Sheremeta, R. Visibility of Contributions and Cost of Inflation: An experiment on public goods.

10-19 Sheremeta, R. and Shields, T. Do Investors Trust or Simply Gamble?

10-18 Deck, C. and Sheremeta, R. Fight or Flight? Defending Against Sequential Attacks in the Game of Siege.

10-17 Deck, C., Lin, S. and Porter, D. Affecting Policy by Manipulating Prediction Markets:

Experimental evidence.

10-16 Deck, C. and Kimbrough, E. Can Markets Save Lives? An Experimental Investigation of a Market for Organ Donations.

10-15 Deck, C., Lee, J. and Reyes, J. Personality and the Consistency of Risk Taking Behavior: Experimental evidence.

10-14 Deck, C. and Nikiforakis, N. Perfect and Imperfect Real-Time Monitoring in a Minimum-Effort Game.

10-13 Deck, C. and Gu, J. Price Increasing Competition? Experimental Evidence.

10-12 Kovenock, D., Roberson, B., and Sheremeta, R. The Attack and Defense of Weakest-Link Networks.

10-11 Wilson, B., Jaworski, T., Schurter, K. and Smyth, A. An Experimental Economic History of Whalers' Rules of Capture.

10-10 DeScioli, P. and Wilson, B. Mine and Thine: The territorial foundations of human property.

10-09 Cason, T., Masters, W. and Sheremeta, R. Entry into Winner-Take-All and Proportional-Prize Contests: An experimental study.

10-08 Savikhin, A. and Sheremeta, R. Simultaneous Decision-Making in Competitive and Cooperative Environments. 
10-07 Chowdhury, S. and Sheremeta, R. A generalized Tullock contest.

10-06 Chowdhury, S. and Sheremeta, R. The Equivalence of Contests.

10-05 Shields, T. Do Analysts Tell the Truth? Do Shareholders Listen? An Experimental Study of Analysts' Forecasts and Shareholder Reaction.

10-04 Lin, S. and Rassenti, S. Are Under- and Over-reaction the Same Matter? A Price Inertia based Account.

10-03 Lin, S. Gradual Information Diffusion and Asset Price Momentum.

10-02 Gjerstad, S. and Smith, V. Household Expenditure Cycles and Economic Cycles, 1920 - 2010.

10-01 Dickhaut, J., Lin, S., Porter, D. and Smith, V. Durability, Re-trading and Market Performance.

\section{9}

09-11 Hazlett, T., Porter, D., and Smith, V. Radio Spectrum and the Disruptive Clarity OF Ronald Coase.

09-10 Sheremeta, R. Expenditures and Information Disclosure in Two-Stage Political Contests.

09-09 Sheremeta, R. and Zhang, J. Can Groups Solve the Problem of Over-Bidding in Contests?

09-08 Sheremeta, R. and Zhang, J. Multi-Level Trust Game with "Insider" Communication.

09-07 Price, C. and Sheremeta, R. Endowment Effects in Contests.

09-06 Cason, T., Savikhin, A. and Sheremeta, R. Cooperation Spillovers in Coordination Games.

09-05 Sheremeta, R. Contest Design: An experimental investigation.

09-04 Sheremeta, R. Experimental Comparison of Multi-Stage and One-Stage Contests.

09-03 Smith, A., Skarbek, D., and Wilson, B. Anarchy, Groups, and Conflict: An experiment on the emergence of protective associations.

09-02 Jaworski, T. and Wilson, B. Go West Young Man: Self-selection and endogenous property rights.

09-01 Gjerstad, S. Housing Market Price Tier Movements in an Expansion and Collapse.

\section{8}

08-09 Dickhaut, J., Houser, D., Aimone, J., Tila, D. and Johnson, C. High Stakes Behavior with Low Payoffs: Inducing preferences with Holt-Laury gambles.

08-08 Stecher, J., Shields, T. and Dickhaut, J. Generating Ambiguity in the Laboratory. 
08-07 Stecher, J., Lunawat, R., Pronin, K. and Dickhaut, J. Decision Making and Trade without Probabilities.

08-06 Dickhaut, J., Lungu, O., Smith, V., Xin, B. and Rustichini, A. A Neuronal Mechanism of Choice.

08-05 Anctil, R., Dickhaut, J., Johnson, K., and Kanodia, C. Does Information Transparency Decrease Coordination Failure?

08-04 Tila, D. and Porter, D. Group Prediction in Information Markets With and Without Trading $\underline{\text { Information and Price Manipulation Incentives. }}$

08-03 Thomas, C. and Wilson, B. Horizontal Product Differentiation in Auctions and Multilateral Negotiations.

08-02 Oprea, R., Wilson, B. and Zillante, A. War of Attrition: Evidence from a laboratory experiment on market exit.

08-01 Oprea, R., Porter, D., Hibbert, C., Hanson, R. and Tila, D. Can Manipulators Mislead Prediction Market Observers? 